Review

\title{
Applications of Carbon Dots for the Photocatalytic and Electrocatalytic Reduction of $\mathrm{CO}_{2}$
}

\author{
Beatriu Domingo-Tafalla ${ }^{1,2} \mathbb{D}$, Eugenia Martínez-Ferrero ${ }^{1} \mathbb{D}$, Federico Franco ${ }^{1, *} \mathbb{D}$ and Emilio Palomares-Gil ${ }^{1,3, *}$ \\ 1 Institute of Chemical Research of Catalonia, The Barcelona Institute of Science and Technology (ICIQ-BIST), \\ Avda. Països Catalans, 16, E-43007 Tarragona, Spain; bdomingo@iciq.es (B.D.-T.); emartinez@iciq.es (E.M.-F.) \\ 2 Departament d'Enginyeria Electrònica, Elèctrica i Automàtica, Universitat Rovira i Virgili, \\ Avda. Països Catalans, 26, E-43007 Tarragona, Spain \\ 3 ICREA, Passeig Lluís Companys 23, E08010 Barcelona, Spain \\ * Correspondence: ffranco@iciq.es (F.F.); epalomares@iciq.es (E.P.-G.); Tel.: +34-97-792-0200 (F.F. \& E.P.-G.)
}

Citation: Domingo-Tafalla, B.; Martínez-Ferrero, E.; Franco, F.; Palomares-Gil, E. Applications of Carbon Dots for the Photocatalytic and Electrocatalytic Reduction of $\mathrm{CO}_{2}$. Molecules 2022, 27, 1081. https://doi.org/10.3390/ molecules27031081

Academic Editor: Yucheng Lan

Received: 17 December 2021

Accepted: 31 January 2022

Published: 6 February 2022

Publisher's Note: MDPI stays neutral with regard to jurisdictional claims in published maps and institutional affiliations.

Copyright: (C) 2022 by the authors. Licensee MDPI, Basel, Switzerland. This article is an open access article distributed under the terms and conditions of the Creative Commons Attribution (CC BY) license (https:// creativecommons.org/licenses/by/ $4.0 /)$.

\begin{abstract}
The photocatalytic and electrocatalytic conversion of $\mathrm{CO}_{2}$ has the potential to provide valuable products, such as chemicals or fuels of interest, at low cost while maintaining a circular carbon cycle. In this context, carbon dots possess optical and electrochemical properties that make them suitable candidates to participate in the reaction, either as a single component or forming part of more elaborate catalytic systems. In this review, we describe several strategies where the carbon dots participate, both with amorphous and graphitic structures, in the photocatalysis or electrochemical catalysis of $\mathrm{CO}_{2}$ to provide different carbon-containing products of interest. The role of the carbon dots is analyzed as a function of their redox and light absorption characteristics and their complementarity with other known catalytic systems. Moreover, detailed information about synthetic procedures is also reviewed.
\end{abstract}

Keywords: carbon dots; graphene quantum dots; photocatalysis; electrocatalysis; $\mathrm{CO}_{2}$ reduction; single atom; metal free

\section{Introduction}

Anthropological $\mathrm{CO}_{2}$ emissions are the primary driver of global climate change, since their growth from mid-20th century has actually reached 36 billion tons per year [1]. As a way to contribute to climate change mitigation, $\mathrm{CO}_{2}$ capture and utilization has started to attract attention worldwide because it can turn waste $\mathrm{CO}_{2}$ emissions into valuable products, such as chemicals and fuels [2], contributing to a sustainable economy with a closed carbon cycle.

The catalytic $\mathrm{CO}_{2}$ reduction reaction $\left(\mathrm{CO}_{2} \mathrm{RR}\right)$ driven by light (photocatalysis) or electricity (electrocatalysis) powered by renewable sources are promising approaches to replicate nature's process of $\mathrm{CO}_{2}$ conversion into chemical energy [3]. They are extremely attractive ways of using $\mathrm{CO}_{2}$ as a feedstock for the production of fuels or valueadded monocarbon $\left(\mathrm{C}_{1}\right)$ and multicarbon $\left(\mathrm{C}_{>2}\right)$ chemicals, such as formic acid/formate $\left(\mathrm{HCOOH} / \mathrm{HCOO}^{-}\right)$, carbon monoxide $(\mathrm{CO})$, methane $\left(\mathrm{CH}_{4}\right)$, ethylene $\left(\mathrm{C}_{2} \mathrm{H}_{4}\right)$, methanol $\left(\mathrm{CH}_{3} \mathrm{OH}\right)$, or ethanol $\left(\mathrm{C}_{2} \mathrm{H}_{5} \mathrm{OH}\right)$. Due to the wide variety of carbonaceous products that can be potentially formed, as well as the competitive side Hydrogen Evolution Reaction (HER) which typically lowers the efficiency of the overall $\mathrm{CO}_{2} \mathrm{RR}$ process in aqueous media, the selectivity toward the formation of a specific target product is the major challenge for achieving an efficient $\mathrm{CO}_{2} \mathrm{RR}$. Furthermore, the extreme inertness and stability of the $\mathrm{CO}_{2}$ molecule pose both thermodynamic and kinetic obstacles to an efficient $\mathrm{CO}_{2}$ activation and conversion [4]. Several transition metal-based catalysts have been reported so far for efficient electro- and photocatalytic $\mathrm{CO}_{2} \mathrm{RR}$, including homogeneous and heterogenized molecular catalysts, reticular 2D/3D materials (e.g., metal-organic frameworks (MOFs), 
covalent-organic frameworks (COFs)), single atom catalysts and nanostructured heterogeneous materials based on metal or metal-oxide surfaces [5-9]. However, the performances of the state-of-the-art systems developed so far need to be further improved to fulfill the applicative and technological requirements in terms of cost, selectivity and durability.

Carbonaceous materials, including carbon nanotubes (CNT), graphite, graphene and porous carbon, are known to possess good chemical and mechanical stability, excellent electrical conductivity and tunable electrical structure, representing ideal components for energy conversion devices [10-12]. In the past few years, various carbon-based nanomaterials have been successfully employed for an efficient catalytic $\mathrm{CO}_{2}$ reduction, either in combination of metal/metal oxide-based catalysts or as metal-free catalysts themselves [13-16]. They have even been reported for the obtention of $C_{\geq 2}$ products $[13,17]$ on account of their capability to decrease the energy barrier of the $\mathrm{C}-\mathrm{C}$ coupling [18]. An extensive variety of metal-free carbon based catalysts for $\mathrm{CO}_{2} \mathrm{RR}$ have been reviewed elsewhere [10].

Carbon dots (CDs) are a new kind of nanocarbon material and have been gaining attention as promising candidates for the design of novel materials for photocatalytic and electrocatalytic applications [19-25], along with numerous applications in other fields [26-28], since they were first discovered in 2004 [29] (see Scheme 1). CDs are surface-functionalized graphitic or amorphous carbon nanoparticles (size below $10 \mathrm{~nm}$ ) with high chemical stability, excellent photo/electro properties, electron transfers/transport capacities and easy large-scale production $[30,31]$. To date, they have been thoroughly characterized with several techniques, and great progress has been made on tuning their properties by changing the synthetic parameters. In this regard, numerous heteroatom doping strategies have been developed in order to improve their fluorescence properties, i.e., to increase their quantum yields and tune the wavelength emission. However, heteroatom doping also breaks the electroneutrality and provides CDs with a highly improved electronic structure and enhanced catalytic properties. Moreover, the optical properties of CDs have been associated to photoinduced redox characteristics, since the photoexcitation results in desirable charge separation and transfer for photocatalytic applications [32]. Finally, CDs can be doped with Earth abundant metals such as $\mathrm{Fe}, \mathrm{Co}$, and $\mathrm{Mn}$, which, in combination with the heteroatoms $(\mathrm{H})$, could form $\mathrm{M}-\mathrm{H}-\mathrm{C}$ centres which are reported to act as catalytic active sites $[33,34]$.

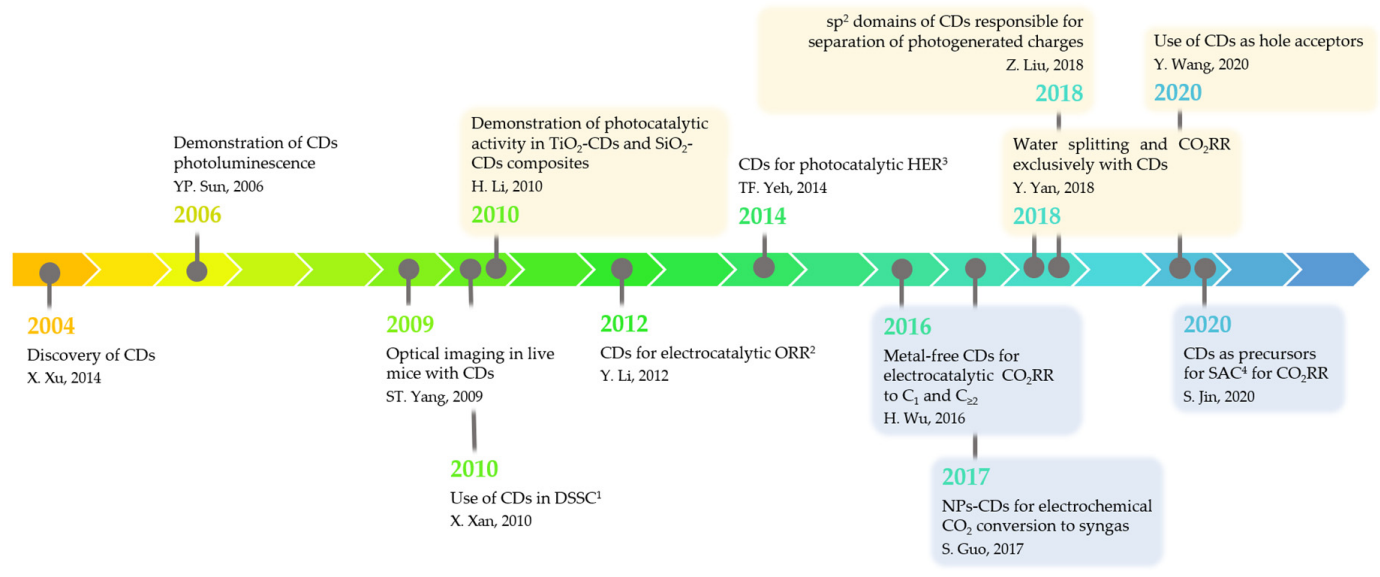

Scheme 1. Timeline with the most relevant applications of CDs in photocatalysis (yellow) and electrocatalysis (blue) for $\mathrm{CO}_{2} \mathrm{RR}$ and in other fields. ${ }^{1}$ DSSC: dye sensitized solar cells, ${ }^{2}$ ORR: oxygen reduction reaction, ${ }^{3}$ HER: hydrogen evolution reaction, ${ }^{4}$ SAC: single atom catalysts $[30,31,29,28,50,21,20,17,52,45,47,90,48]$.

This review aims to provide a general overview about the applications of CDs for photocatalytic and electrocatalytic $\mathrm{CO}_{2} \mathrm{RR}$, critically assessing the role of the $\mathrm{CDs}$ in the reported catalytic systems. In the next section, the main methods recently proposed for the synthesis, purification, and characterization of the CDs will be presented, as well as the most commonly used strategies for CDs doping and hybridization with metal/metal-oxide 
materials. The applications of $\mathrm{CDs}$ for photocatalytic and electrocatalytic $\mathrm{CO}_{2} \mathrm{RR}$ will be discussed in the Sections 3 and 4, respectively, systematically comparing the metal-free CDs catalysts with the metal composite materials. Based on the data herein presented, the role of $\mathrm{CDs}$ in the catalytic $\mathrm{CO}_{2} \mathrm{RR}$ process will be discussed, providing some hints on future perspectives of the research field.

\section{Strategies for CDs Synthesis}

\subsection{Synthesis Methods}

The preparation of CDs can be described by two main synthetic methodologies: the top-down approach, which consists in the breaking of bulk carbon structures, and the bottom-up approach, which refers to the formation of nanoparticles from molecular precursors via chemical reactions (Figure 1). By tuning the reaction precursors and synthetic procedures, a vast number of CDs and heteroatom-doped CDs with distinct properties and applications can be obtained. Indeed, a comparison between top-down and bottom-up approaches showed that CDs and N-doped CDs obtained from these two methods have differentiated photoluminescence properties and chemical states. For instance, both types of CDs may feature varying distributions of functional groups (i.e., hydroxyl, carbonyl and carboxyl, amine, and pyridinic and pyrrolic N), and notable changes in $\mathrm{sp}^{3}$-carbon content depending on the specific synthetic conditions [35].

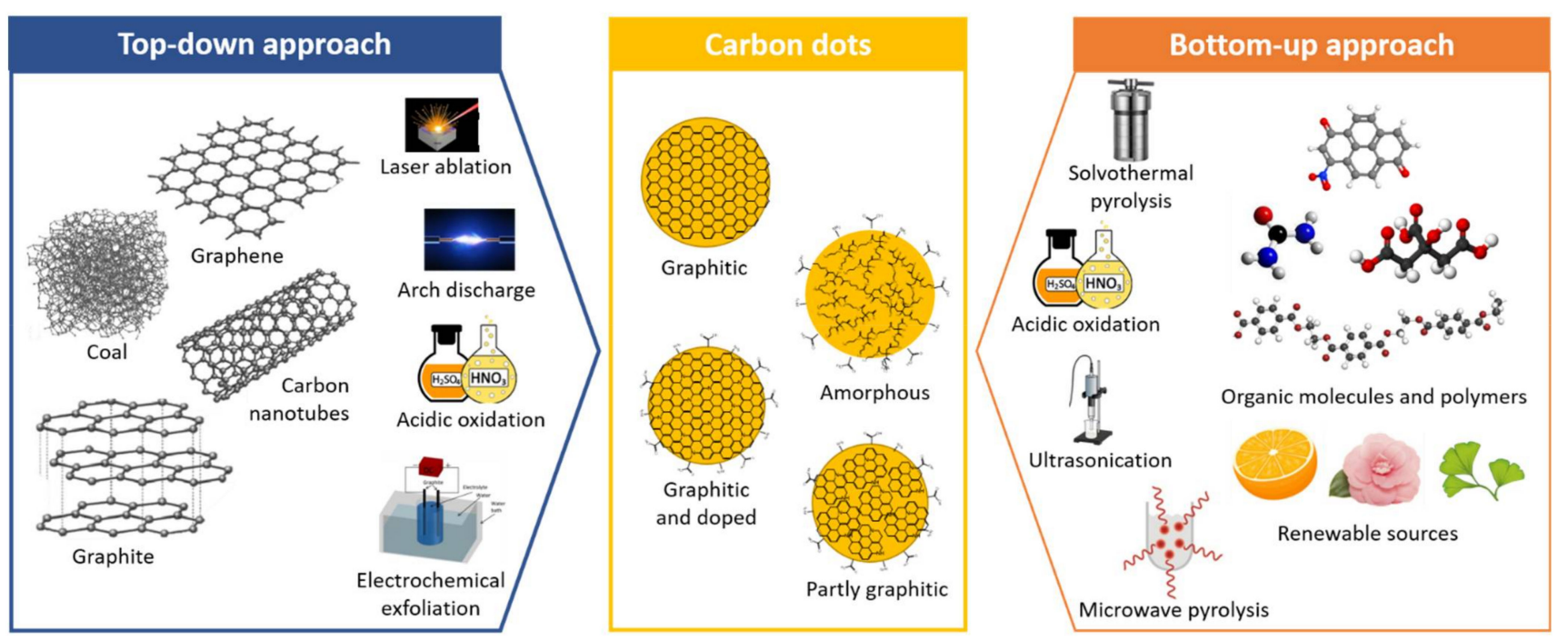

Figure 1. Schematic description of the different approaches followed for the synthesis of carbon dots.

\subsubsection{Top-Down Approach}

Top-down methods comprise physical and chemical strategies to break the carbon structures. This approach usually results in dots with high crystallinity and intact structures, most commonly named graphene quantum dots (GQDs) because of the typical graphitic organization of the carbon atoms in the nanoparticle. Arc-discharge was the first topdown method to isolate GQDs during the synthesis and purification of Single-wall carbon nanotubes (CNTs) [29]. This technique consists of breaking big-size carbon compounds with an electrical arc-discharge, while their post-synthetic acid oxidation enables to obtain surface passivated, stable and heteroatom doped GQDs. Alternatively, GDQs can be obtained by laser ablation, which consists of removing material from a solid surface by irradiating with a laser beam [36]. Carbon sources that have been employed to obtain GQDs following this method include graphite immersed in polyethyleneimine (PEI) and ethylenediamine (EDA) [37], activated carbon suspended in n-heptane [38], or solid carbon immersed in acetone [39]. Moreover, acidic oxidation is the treatment of graphene oxide, soot, coal, carbon black, or activated carbon with an oxidizing agent at temperatures of 60-100 ${ }^{\circ} \mathrm{C}$, which exposes the edge sites from which the carbon material is exfoliated. For 
example, GQDs have been obtained from Multi-Walled CNTs oxidized with a mixture of $\mathrm{HNO}_{3} / \mathrm{H}_{2} \mathrm{SO}_{4}$ [40-42], from carbonized coal treated with $\mathrm{HNO}_{3}$ [43], from anthracite coal treated with $\mathrm{H}_{2} \mathrm{SO}_{4}$ and $\mathrm{HNO}_{3}$ [44] and from graphene oxide treated with periodic acid, $\mathrm{H}_{2} \mathrm{SO}_{4}$ or $\mathrm{HCl}[17,45-47]$. Furthermore, the electrochemical exfoliation of carbonbased materials revealed to be an effective synthetic method to obtain GDQs. It consists in applying a static potential between two electrodes acting as the carbon sources, including CNTs [48], graphite rods [49-52], and reduced graphene oxide films [53]. Furthermore, GQDs have been produced via electrochemical exfoliation in large scale by applying a constant voltage of $15 \mathrm{~V}$ between a pre-baked carbon anode and stainless steel (cathode) [54], or from two clean carbon rods placed in parallel in deionised water, with static potential of 15-60 V [55]. Finally, other top-down techniques following physical routes can be found in the literature, such as microwave (MW) irradiation [56] and ultrasounds [57,58], but they are less common.

Moreover, GQDs usually require heteroatom doping, mostly with nitrogen, to enhance their photoluminescent or catalytic properties. Top-down synthesized GQDs have been $\mathrm{N}$-doped by thermal treatment with ammonia solution [52,55] or in situ with solvents, such as dimethylformamide (DMF) [17,59], which decompose at high temperatures forming ammonia and other compounds.

\subsubsection{Bottom-Up Approach}

Bottom-up methods tend to yield CDs with an amorphous carbon core and abundant doping sites and surface functional groups. The most common synthetic route is the hydrothermal/solvothermal method, based on a thermal decomposition of organic precursors in aqueous or organic solution at temperatures typically in a range between 100 and $250{ }^{\circ} \mathrm{C}$. Similar conditions can be achieved with the MW synthesis, which is another common, effective way to synthesize CDs in a shorter reaction time [60]. For both types of synthesis, depending on the temperature or power, reaction time and precursor, the physicochemical properties of the CDs, such as size, crystallinity, solubility, can be controlled. Precursors can be obtained from renewable sources, such as orange juice [61], shrimp egg [62], ginkgo leaves [63], extract of waste tea [64], pine pollen [65], Camellia japonica flowers [66], or waste cotton linter [42]. Other renewable sources are reviewed elsewhere [67]. However, the most conventional sources are commercial precursors, such as citric acid [68-74], glucose [75-78], ascorbic acid [79,80], polyethylene glycol [81,82], and ethylene glycol [83]. Other heteroatom-containing precursors, such as urea [68,84-90] chitosan [91-94], ethylenediamine $[37,71,73,77,95]$, thiourea [72,96], cysteine [74], cetrimonium bromide (CTAB) [97], phenylenediamine [98], ammonium citrate [99], and nitropyrene [100,101] are used to dope the CDs with Nitrogen and/or Sulphur (N-CDs, S-CDs and N,S-CDs). N-doping can also originate from thermal treatment of the carbon precursor in $\mathrm{N}$-containing solvents such as acetonitrile [90].

Another facile approach is ultrasonication, which is the application of intense ultrasound waves into liquids and slurries [102]. For instance, glucose in $\mathrm{NaOH}$ aqueous solution has been recurrently use to obtain CDs by ultrasonication [103-109]. Other approaches for synthesis of CDs have been explored, although they are less common. For instance, acidic oxidation of organic molecules with strong acids at low temperatures $\left(60-100{ }^{\circ} \mathrm{C}\right)$ is an approach with reduced energetic consumption compared to the pyrolytic methods. CDs can be obtained from the oxidation of sucrose [110], ethylene glycol [111], or even pumpkin [112]. Alternative processes are microplasma assisted synthesis at room temperature from o-phenylendiamine [113], thermochemical processing without solvent from N-succinimide [114], citric acid and branched polyethylenimine (BPEI) [115], or only citric acid [116]. Recently, chiral carbon dots have been obtained from cysteine with radical-assisted chemistry at room temperature with $\mathrm{Cu}(\mathrm{II})$ as a catalyst [117].

Numerous studies have thoroughly investigated the characteristics of CDs as a function of the nature of the precursors and synthesis conditions. For instance, Miao et al. reported that, by regulating the thermal-pyrolysis temperature and $\mathrm{N}$-doping, the maxi- 
mum emission of the resulting N-CDs gradually shifts from blue to red through controlling the extent of graphitization and the amount of surface functional groups, $-\mathrm{COOH}$ and $-\mathrm{NH}_{2}$ [87]. Huan Yuan et al. performed a similar study to demonstrate that surfacepassivation of the N-CDs by N-doping can improve the emission efficiency due to the single electron transition resulting from the single functional groups [118]. Khavlyuk et al. found that the CDs appearance from amorphous or well-carbonized spherical particles to onion-like ones is controlled by solvent polarity, whereas the degree of N-doping and the nature of the emissive centers in N-CDs are mostly influenced by the thermal treatment conditions [119]. The systematic study of Crista et al. revealed that both the solvothermal and microwave assisted thermal synthesis of N-CDs from citric acid and urea led to nanoparticles with similar sizes, identical excitation-dependent blue-to-green emission, and similar surface-functionalization. However, it was found that microwave strategy is more efficient towards N-doping than hydrothermal synthesis. Furthermore, microwave routes were found to be more suitable for high-yield synthesis ( 27-29\%), while hydrothermal synthesis present almost negligible synthesis yields ( 2\%) [120]. Finally, Sendão et al. conducted a comparative life cycle assessment of solvothermal and microwave-assisted thermal synthesis routes for N-CDs derived from citric acid and urea. They reported that the environmental cost of the electrical consumption during the hydrothermal synthesis advises against the use of this technique. Therefore, the most sustainable option in order to obtain high quantum yield N-CDs is microwave-assisted treatment of an aqueous solution of urea and citric acid [68].

The fundamental steps taking place in the bottom-up formation of CDs have been thoroughly investigated. Rigodanza et al. suggested that the formation of N-CDs from ethylenediamine and L-arginine precursors can be divided into four consecutive steps (Figure 2): (i) aggregation of small organic molecules, (ii) formation of a dense core and with an extended shell, (iii) collapse of the shell, and (iv) aromatization of the core. The findings also reveal that the N-CDs unique fluorescence is achieved already after stage (iii), when N-CDs display the final core-shell structure [121].

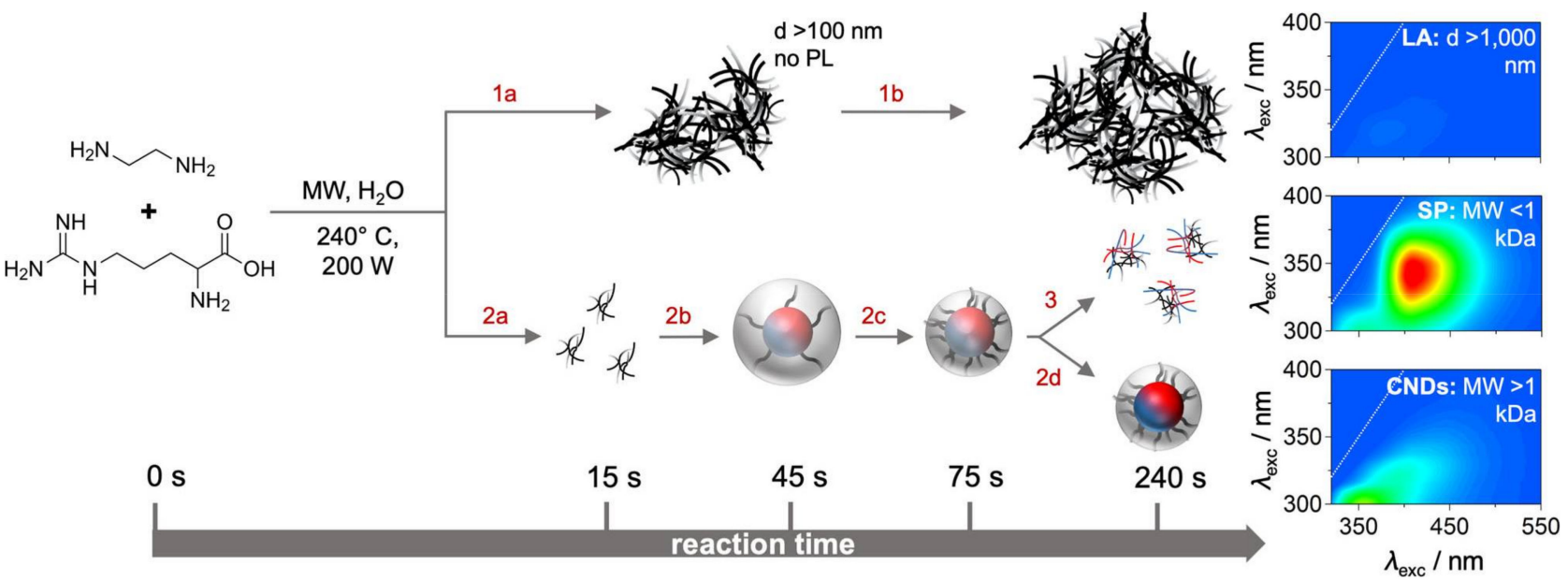

Figure 2. Proposed formation of N-CDs from arginine and ethylenediamine as precursors: (step 2a) aggregation of organic molecules (15-45 s), (step 2b) core and shell formation (30-45 s), (step 2c) shell collapse (45-75 s), and (step 2d) formation of aromatic groups within core (120-240 s). By-products are large aggregates $>100 \mathrm{~nm}$ (steps $1 \mathrm{a}-1 \mathrm{~b}$ ) and small particles $<1 \mathrm{kDa}$ (step 3 ). Right insets: 2D excitation-emission spectra of filter residue (LA, top), dialysate (SP, middle), and carbon nanodots (CNDs) (bottom, $0.03 \mathrm{mg} \mathrm{mL}^{-1}$ in MilliQ water $25^{\circ} \mathrm{C}$ ), intensity is expressed in relative units. Reprinted with permission from reference [121]. Copyright (C) 2021, Nature Publishing Group.

\subsection{Purification of Carbon Dots}

A few studies report the coexistence of different species in the final CD product $[70,74,85,86]$. In general, low synthesis temperature and short times tend to favor 
the production of fluorophores (small molecules), while high synthesis temperatures and long times are needed to form conjugated $\pi$ domains (carbon cores). As a final result, both species, as well as carbon cores functionalized with fluorophores, are considered to coexist in the final product in different amounts depending on the synthetic conditions. Therefore, a variety of separation techniques have been used to purify CDs for further applications, including dialysis with membrane molecular weight cutoffs (MWCO) of 1 to $3.5 \mathrm{kD}[37,47,122-126]$ ultrafiltration through centrifugal filter devices with different MWCO [127,128], denaturing polyacrylamide gel electrophoresis (PAGE) [129], silica gel column chromatography $[49,70,74]$, and Sephadex column chromatography [130].

There are, in the literature, more extensive investigations regarding the purification of CDs. For instance, Zhang et al. gradually separated GQDs obtained from the acidic oxidation of graphene oxide using dialysis tubes with MWCO of 1, 3.5 and $7 \mathrm{kDa}$. The size of GQDs with molecular weight between 1 and 3.5, 3.5 and 7, and $>7 \mathrm{kDa}$ were $<5 \mathrm{~nm}, 10$ and $15 \mathrm{~nm}$, and 16 and $20 \mathrm{~nm}$, respectively, they showed different fluorescent colors and increased Quantum Yields with the size [122]. Moreover, Song et al. synthesized N-CDs from pyrolysis of citric acid and ethylenediamine, investigating the different fractions of the product via Silica gel column chromatography and via dialysis with a $3.5 \mathrm{kDa} \mathrm{MWCO}$ membrane [70]. They showed that the first fractions to leave the column were fluorophores, followed by carbon cores with attached fluorophores, and, finally, the carbon cores. When separated by dialysis, both the fraction inside the dialysis bag and that outside showed fluorescence, proving that small fluorescent molecules cross the membrane but fluorescent material (either carbon cores or carbon cores with attached fluorophores) remain in the sample. Such findings were in accordance with the work of Hinterberg et al., who synthesized $\mathrm{N}-\mathrm{CD}$ from hydrothermal pyrolysis of cysteine and citric acid and extracted the different fractions through Silica gel column chromatography [74]. Furthermore, Michaud et al. synthesized N-CDs from the pyrolysis of citric acid and cysteine and achieved a complete separation of all the components by means of two step gradient chromatography: first, silica-gel column chromatography and, second, high performance liquid chromatography (HPLC). At the end of the process, up to six components were extracted [131].

\subsection{Metal Doping, Modification, and Post-Processing of Carbon Dots}

The introduction of metals into the carbon matrix of the CDs, modifies the charge density, which, in turn, affects the physicochemical properties of CDs and can affect the catalytic properties. Hydrothermal strategies are the most common ones for the synthesis of metal-doped CDs. In such procedures, the metal precursor is mixed in solution with the organic carbon/nitrogen source and the mixture is thermally treated. Iron is the most reported dopant metal and has been introduced from different sources, such as iron benzoate [132], $\mathrm{FeCl}_{3}$ [133-135], or Fe-gluconate [136]. Cobalt has been introduced from $\mathrm{CoCl}_{2}$ [137] and Co-gluconate [136]. Copper has been introduced from $\mathrm{CuCl}_{2}$ [138,139], $\mathrm{Cu}\left(\mathrm{NO}_{3}\right)_{2}$ [140], $\mathrm{Cu}(\mathrm{Ac})_{2}$ [64], and $\mathrm{CuSO}_{4}$ [141]. Other metal sources are Zn-gluconate [142] and $\mathrm{MnCl}_{2}$ [143]. Finally, metalorganic complexes have also been used as carbon, nitrogen, and metal precursors at the same time. For instance, Nickel porphyrin [78] and $\mathrm{Na}_{2}[\mathrm{Cu}(\mathrm{EDTA})]$ [144] have been used to synthesize Nickel and Copper doped-CDs, respectively.

In addition to metal atoms, the presence of surface functional groups of CDs strongly affects their properties. Amino, carboxy, and hydroxy groups are the most common ligands encountered in CDs and N-CDs, but they can also be introduced via covalent and noncovalent modification. There are reports in the literature describing the covalent modification (via amide coupling reactions, silylation, and other reactions including esterification, sulfonylation, and copolymerization) and about noncovalent modifications ( $\pi$ interactions, complexation/chelation, and electrostatic interactions), which accurately improve the luminescence properties and allow for novel applications, such as drug delivery, bioimaging, and ion or detection of small molecules. Thorough enumeration and explanation of these modifications and their applications is reviewed elsewhere [123]. 
Lastly, some applications require the combination of CDs with other materials, such as the few examples described here. For instance, Qu et al. co-crystallized CDs in a matrix of isophthalic acid or melamine, which strengthened the hydrogen bonds between CDs and the host matrix and, in turn, resulted in CDs with room temperature phosphorescence properties [145]. Sun et al. confined CDs within a $\mathrm{SiO}_{2}$ matrix, constructing an effective multi-confinement effect which lead to ultralong room temperature phosphorescence lifetime and exceptional stability [146]. Guo et al. embedded CDs in europium ions $\left(\mathrm{Eu}^{3+}\right)$-doped Metal Organic Framework (MOF) by simple stirring the preparation at room temperature for label-free ratiometric fluorescence detection of $\mathrm{Fe}^{3+}$ ions [147]. Sun et al. dispersed CDs into a cross-linked silica network on the surface of $\mathrm{SiO}_{2}$ nanoparticles to produce an efficient full-color emitting composite [148]. Zhou et al. co-crystallized CDs with cyanuric acid in order to modulate the bandgap emissions of CDs and produce highly emissive solid composite CD-based materials [149]. Li et al. combined MOFs and CDs by embedding the CDs into the MOF structure or by decorating the MOF surface with CDs in order to assess which approach is more favorable for charge separation and transfer [150]. Cheng et al. electrostatically assembled CDs with boron nitride nanosheets that exhibit thermal quenching resistance and white luminescence [151]. Finally, Jiang et al. embedded CDs in a boric acid and urea matrix using microwave heating which exhibited afterglow properties [152].

\subsection{Synthesis of CDs-Composites for $\mathrm{CO}_{2}$ Reduction}

Numerous catalysts reviewed in this work are made of CDs or GQDs combined with other metal or metal oxide structures. Synthetic approaches of these catalysts include the synthesis of both components separately followed by physical or chemical interaction, to in situ synthesis of both components. The most utilized components are nanostructured $\mathrm{TiO}_{2}$, $\mathrm{Cu}_{\mathrm{x}} \mathrm{O}$ structures and $\mathrm{C}_{3} \mathrm{~N}_{4}$ nanosheets.

CDs decoration of $\mathrm{TiO}_{2}$ nanoparticles (NPs) has been reported to occur by directly stirring and ultrasonicating GQDs or $\mathrm{CDs}$ and $\mathrm{TiO}_{2} \mathrm{NPs}$ in solution [49,72]. Following another approach, Wei et al. decorated $\mathrm{TiO}_{2}$ nanotube arrays with both Ag NPs and CDs by a one-step solvothermal method combining the $\mathrm{TiO}_{2}$ nanotube arrays, $\mathrm{AgNO}_{3}$ and ethylene glycol as the carbon source (Figure 3A) [83].

A variety of copper structures have been combined with CDs. For instance, H. Li et al. supported $\mathrm{CDs}$ on $\mathrm{Cu}_{2} \mathrm{O}$ particles by in situ pyrolyzing glucose with the $\mathrm{Cu}_{2} \mathrm{O}$ particles [105]. In another work, Chen et al. obtained $\mathrm{CuO}$-nanorods by ultrasonication of $\mathrm{N}-$ GQDs or N-CDs dispersed in ethanol with $\mathrm{CuO}$ nanorods, which were annealed at $300{ }^{\circ} \mathrm{C}$ in a second step [59]. Thirdly, Guo et al. fabricated GQDs-CuO nanocorals by simply sonicating $\mathrm{N}-\mathrm{GQD}$ with $\mathrm{Cu}_{2} \mathrm{O}$ nanocorals. The obtained $\mathrm{N}-\mathrm{GQDs}-\mathrm{Cu}_{2} \mathrm{O}$ nanocorals were painted on carbon paper and reduced electrochemically to GQDs-CuO nanocorals [52].

The synthesis of $C D s-C_{3} N_{4}$ hybrids have been studied in several reports. Song et al. and Wang et al. prepared CDs-decorated $\mathrm{C}_{3} \mathrm{~N}_{4}$ from hydrothermally treated CDs and protonated $C_{3} N_{4}$ dispersed in water $[89,103]$. Q. Li et al. decorated $C_{3} N_{4}$ nanosheets with $C D$ s by hydrothermally treating the $\mathrm{C}_{3} \mathrm{~N}_{4}$ in an ethanol and $\mathrm{H}_{2} \mathrm{O}_{2}$ mixed solution. By adjusting the volume ratio of ethanol and $\mathrm{H}_{2} \mathrm{O}_{2}$, different quantities of CDs could be anchored [153]. CDs- $\mathrm{C}_{3} \mathrm{~N}_{4}$ hybrids have also been combined with a third component. For instance, Zhao et al. synthesized Au-nanoparticles decorated with GQDs- $\mathrm{C}_{3} \mathrm{~N}_{4}$ following a two-step method. GQDs- $\mathrm{C}_{3} \mathrm{~N}_{4}$ was obtained by hydrothermally treating a mixture of GQDs with urea at $550{ }^{\circ} \mathrm{C}$. The obtained solid was dispersed in the presence of $\mathrm{HAuCl}_{4}$, which was irradiated in order to obtain the final catalyst [50]. Jo et al. prepared a N-CDs/CoAl-layered double hydroxide/g- $\mathrm{C}_{3} \mathrm{~N}_{4}$ hybrid. For such purpose, $\mathrm{C}_{3} \mathrm{~N}_{4}$ and $\mathrm{N}-\mathrm{CD}$ s were ultrasonicated in an aqueous solution containing cobalt and aluminum salts. Subsequently, urea and $\mathrm{NH}_{4} \mathrm{~F}$ were added followed by hydrothermal treatment at $120^{\circ} \mathrm{C}$ [88]. Finally, Guo et al. prepared a $\mathrm{Co}_{3} \mathrm{O}_{4}$-GQDs- $\mathrm{C}_{3} \mathrm{~N}_{4}$ composite by hydrothermally treating GQDs, $\mathrm{Co}_{3} \mathrm{O}_{4}$ and melamine at $500{ }^{\circ} \mathrm{C}$ [51]. 


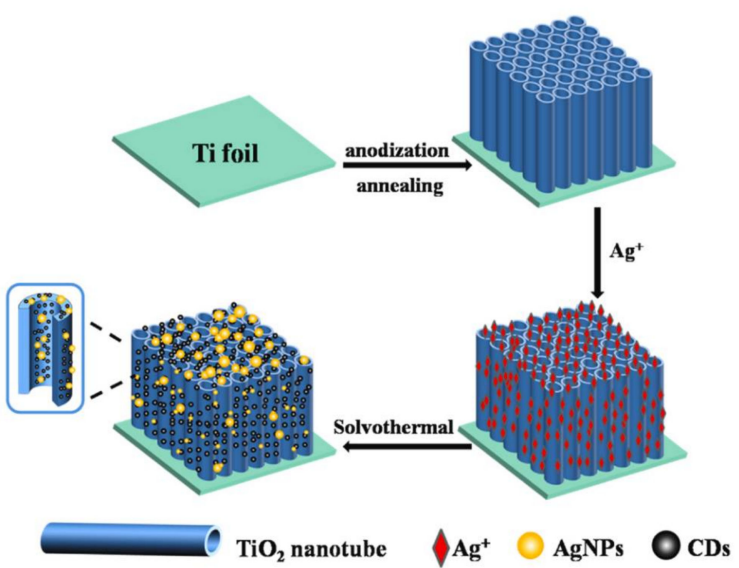

(A)

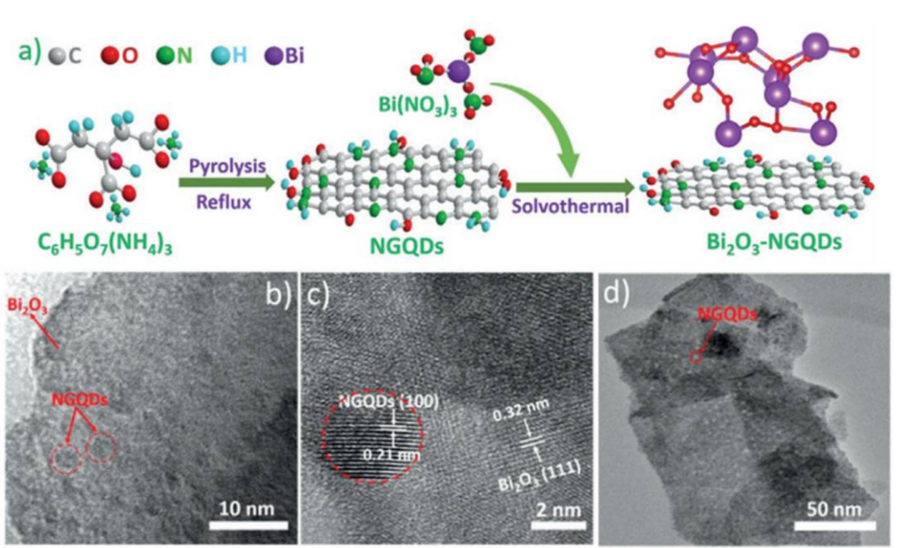

(B)

Figure 3. Two examples of the preparation of composite materials containing CDs or GQDs: (A) $\mathrm{TiO}_{2}$ nanotube arrays decorated with CDs and Ag NPs. Reprinted with permission from reference [83]. Copyright 2020 Elsevier Ltd. (B) $\mathrm{Bi}_{2} \mathrm{O}_{3}$ nanosheets decorated with CDs: Illustration of the preparation of $\mathrm{Bi}_{2} \mathrm{O}_{3}$-NGQDs (a), Transmission electron microscopy (TEM) (b,d) and high resolution TEM (HRTEM) (c) images. Reprinted with permission from reference [99]. Copyright 2018, John Wiley and sons.

Other examples of composite materials have also been described. For instance, Gao et al. prepared CDs-covered porous $\mathrm{Ag}$ by directly reducing porous $\mathrm{Ag}_{2} \mathrm{O}$ with $\mathrm{D}$ glucose in $\mathrm{NaOH}$ solution [106]. In a similar work, Fu et al. synthesized single-crystalline $\mathrm{Au}$ NPs covered with CDs, which were in situ synthesized directly from surfactants onto Au NPs [97]. As a reverse approach, Cao et al. functionalized CDs with oligomeric poly(ethylene glycol) diamine and coated the dots with gold or platinum by simple solutionphase photolysis of $\mathrm{HAuCl}_{4}$ or $\mathrm{H}_{2} \mathrm{PtCl}_{6}$, taking advantage of the fact that carbon particles acted as electron donors to reduce the metal salts [107]. Chen et al. combined $\mathrm{Bi}_{2} \mathrm{O}_{3}$ nanosheets and CDs by solvothermal treatment of Bismuth salt dissolved in polyol media with the presence of CDs (Figure 3B) [99]. Lv et al. obtained N-CDs-decorated $\mathrm{MoS}_{2}$ sheets by thermally treating exfoliated $\mathrm{MoS}_{2}$ with exposed active sites with DMF [154]. Xia et al. synthesized Single atom catalysts (SACs) from GQDs, which were supported on CNTs. The material was obtained by stirring metal salt $(\mathrm{Ni}, \mathrm{Cr}, \mathrm{Mn}, \mathrm{Fe}, \mathrm{Co}, \mathrm{Cu}$, or $\mathrm{Zn}$ ) aqueous solution with GQDs and, afterwards, heating the solid at $500{ }^{\circ} \mathrm{C}$ under $\mathrm{Ar}$ and $\mathrm{NH}_{3}$ [47]. Finally, Zhong et al. embedded Ni-porphyrin based CDs into the channels of a COF by doing an in situ pyrolysis of Ni-porphyrin and glucose in the presence of the COF [78].

\section{Photocatalytic $\mathrm{CO}_{2}$ Reduction}

Due to their optoelectronic characteristics, CDs can act as individual photocatalysts or as part of more complex systems as a means to increase the range of wavelength absorption, to promote the separation of the photogenerated charges or to add stability to the system (see Table 1). In comparison with other carbon-based metal-free materials, CDs are able to photocatalyze $\mathrm{CO}_{2}$ when certain structural conditions are present. For comparison of the activity of the metal-free carbon dots photocatalysts to other carbon-based metal free materials, we refer the readers to [155-157]. 
Table 1. Description of the photocatalytic systems containing carbon dots for $\mathrm{CO}_{2}$ reduction. Two carbon-based materials have also been added as reference.

\begin{tabular}{|c|c|c|c|}
\hline Catalyst & Major Products & Yield & Reaction Conditions \\
\hline g- $\mathrm{C}_{3} \mathrm{~N}_{4} /$ carbon nanosheets [158] & $\mathrm{CO}, \mathrm{CH}_{4}$ & $\begin{array}{c}229 \mu \mathrm{mol} \mathrm{CO} / \mathrm{g} \\
112 \mu \mathrm{mol} \mathrm{CH}_{4} / \mathrm{g} \\
(\text { in } 7 \mathrm{~h})\end{array}$ & $\mathrm{H}_{2} \mathrm{O}$ \\
\hline Graphene Oxide [159] & $\mathrm{CH}_{3} \mathrm{OH}$ & $0.172 \mu \mathrm{mol} / \mathrm{g} \cdot \mathrm{h}$ & $\mathrm{H}_{2} \mathrm{O}$ \\
\hline Ni-PCD@TD-COF ${ }^{1}$ [78] & $\mathrm{CO}, \mathrm{H}_{2}$ & $\begin{array}{c}956 \mu \mathrm{mol} \mathrm{CO} / \mathrm{g} \text { (in } 2 \mathrm{~h}) \\
19 \mu \mathrm{mol} \mathrm{H} / \mathrm{g}(\text { in } 2 \mathrm{~h})\end{array}$ & ACN: $\mathrm{H}_{2} \mathrm{O}: T E O A ~ 3: 1: 1^{2}$ \\
\hline CDs-CN ${ }^{3}[89]$ & $\mathrm{CH}_{3} \mathrm{OH}, \mathrm{CO}$ & $\begin{array}{c}13.9 \mu \mathrm{mol} \mathrm{CH}{ }_{3} \mathrm{OH} / \mathrm{g} \cdot \mathrm{h} \\
0.05 \mu \mathrm{mol} \mathrm{CO} / \mathrm{g} \cdot \mathrm{h}\end{array}$ & $\mathrm{H}_{2} \mathrm{O}$ \\
\hline CDs-FAT $^{4}$ [126] & $\mathrm{CH}_{3} \mathrm{OH}$ & $24.2 \mu \mathrm{mol} \mathrm{CH}{ }_{3} \mathrm{OH} / \mathrm{g} \cdot \mathrm{h}$ & $\mathrm{H}_{2} \mathrm{O}$ \\
\hline CDs-g- $\mathrm{C}_{3} \mathrm{~N}_{4} 3 \%$ wt. [103] & $\mathrm{CH}_{4}, \mathrm{CO}$ & $\begin{array}{c}37.06 \mu \mathrm{mol} \mathrm{CH}_{4} / \mathrm{g} \\
68.8 \mu \mathrm{mol} \mathrm{CO} / \mathrm{g} \\
(\text { in } 10 \mathrm{~h})\end{array}$ & $\mathrm{H}_{2} \mathrm{O}$ \\
\hline CL@CDs $/ \mathrm{Cu}_{2} \mathrm{O}$ [104] & $\mathrm{CH}_{4}, \mathrm{CH}_{3} \mathrm{OH}$ & $\begin{array}{c}99.6 \mu \mathrm{mol} \mathrm{CH}{ }_{3} \mathrm{OH} / \mathrm{g} \cdot \mathrm{h} \\
8 \mu \mathrm{mol} \mathrm{CH} \mathrm{CH}_{4} / \mathrm{g} \cdot \mathrm{h}\end{array}$ & $\mathrm{H}_{2} \mathrm{O}, \mathrm{TEOA}$ \\
\hline $\mathrm{CDs} / \mathrm{Cu}_{2} \mathrm{O}[105]$ & $\mathrm{CH}_{3} \mathrm{OH}$ & $55.7 \mu \mathrm{mol} \mathrm{CH}{ }_{3} \mathrm{OH} / \mathrm{g} \cdot \mathrm{h}$ & $\mathrm{H}_{2} \mathrm{O}$ and dry ice \\
\hline $\mathrm{N}-\mathrm{CDs} / \mathrm{LDH} / \mathrm{g}-\mathrm{C}_{3} \mathrm{~N}_{4}[88]$ & $\mathrm{CH}_{4}$ & $25.4 \mu \mathrm{mol} \mathrm{CH} 4 / \mathrm{g} \cdot \mathrm{h}$ & $\mathrm{H}_{2} \mathrm{O}$ \\
\hline CDs/oxygen doped $\mathrm{C}_{3} \mathrm{~N}_{4}[153]$ & $\mathrm{CH}_{4}$ & $1.2 \mu \mathrm{mol} \mathrm{CH} 4 / \mathrm{g} \cdot($ in $8 \mathrm{~h}$ ) & $\mathrm{H}_{2} \mathrm{O}$ \\
\hline GQDs-BNPTL [44] & $\mathrm{CH}_{3} \mathrm{OH}$ & $0.695 \mu \mathrm{mol} \mathrm{CH}{ }_{3} \mathrm{OH} / \mathrm{g} \cdot \mathrm{h}$ & $\mathrm{H}_{2} \mathrm{O}$ \\
\hline \multirow{2}{*}{ GQDs vs CDs [46] } & CDs: $\mathrm{CO}$ & $400 \mu \mathrm{mol} \mathrm{CO} / \mathrm{g} \cdot \mathrm{h}$ & \multirow{2}{*}{$\mathrm{H}_{2} \mathrm{O}$} \\
\hline & GQDs: $\mathrm{CH}_{4}$ & $983 \mu \mathrm{mol} \mathrm{CH} / \mathrm{g} \cdot \mathrm{h}$, & \\
\hline $\mathrm{N}, \mathrm{S}-\mathrm{CDs} / \mathrm{TiO}_{2}[72]$ & $\mathrm{CO}, \mathrm{CH}_{4}$ & $\begin{array}{c}1.838 \mu \mathrm{mol} \mathrm{CO} \\
1.195 \mu \mathrm{mol} \mathrm{CH} \mathrm{CH}_{4} \\
(\text { in } 6 \mathrm{~h})\end{array}$ & $\mathrm{H}_{2} \mathrm{O}$ \\
\hline GQDs-ANP 5 /biocatalyst [160] & $\mathrm{HCOOH}$ & $\begin{array}{l}198 \mu \mathrm{mol} \mathrm{HCOOH} \\
(\text { in } 2 \mathrm{~h})\end{array}$ & $\mathrm{H}_{2} \mathrm{O}$, TEOA \\
\hline CDs@PEG-Au [161] & $\begin{array}{c}\mathrm{HCOOH} \\
\mathrm{CH}_{3} \mathrm{COOH}\end{array}$ & $\begin{array}{c}1.2 \mu \mathrm{mol} \mathrm{HCOOH} / \mathrm{g} \cdot \mathrm{h} \\
0.06 \mu \mathrm{mol} \mathrm{CH} \mathrm{CHOH}_{3} \mathrm{CO} \cdot \mathrm{h}\end{array}$ & $\mathrm{H}_{2} \mathrm{O}$ \\
\hline
\end{tabular}

${ }^{1} \mathrm{Ni}-\mathrm{PCD}$ : Ni(II) porphyrin attached to a Carbon Dot, confined in the channels of the TD functionalized COF. Ru sensitizer: $\left[\mathrm{Ru}(\mathrm{bpy})_{3}\right] \mathrm{Cl}_{2}{ }^{2} \mathrm{ACN}$ : acetonitrile, TEOA: triethanolamine. ${ }^{3} \mathrm{CN}$ : carbon nanosheets. ${ }^{4}$ FAT: polymer-like carbon nitride. ${ }^{5}$ ANP: 6-amino-2-(9,10-dioxo-6-(erylenelen-3-yl)-4,5-di-p-tolyl-4,5-dihydro-1H-imidazol-1-yl)-9,10-dihydroanthracen-2-yl)-1H- benzo[de]isoquino- line-1,3(2H)-dione.

One of the first studies about the potential of the CDs as photocatalyst was demonstrated in 2010 by Li et al., who reported the photocatalytic activity of GQDs attached to titania $\left(\mathrm{TiO}_{2}\right)$ or silica films. The authors monitored the degradation of methylene blue after light irradiation of the GQDs- $\mathrm{TiO}_{2}$ system, which was shown to be efficient [49]. Shortly after, in 2011, Cao et al. confirmed that the photoinduced charge separation in CDs could be used for photocatalysis [107] (vide infra), opening the door to new experimental observations that are described below.

\subsection{Metal-Free Catalysts}

There are several examples of surface functionalized CDs that do not contain metal or metal oxide loadings. For example, in order to increase the selectivity towards a specific compound of interest, such as $\mathrm{HCOOH}$, Yadav et al. prepared a photocatalyst-biocatalyst integrated system made of GQDs functionalized with the ANP chomophore (6-amino-2-(9,10dioxo-6-[2-[perylen-3-yl]-4,5-di-p-tolyl-4,5-dihydro-1H-imidazol-1-yl]-9,10-dihydroanthracen2-yl)-1H-benzo[de]isoquinoline-1,3(2H)-dione) in combination with a rhodium complex $\left(\left[\mathrm{Cp}{ }^{*} \mathrm{Rh}(\mathrm{bpy}) \mathrm{H}_{2} \mathrm{O}\right]^{2+} \mathrm{Cp}^{*}=\right.$ pentamethylcyclopentadienyl, bpy $=2,2^{\prime}$-bipyridyl), the $\mathrm{NAD}^{+}$/ 
NADH pair and formate dehydrogenase. Although the GQDs or the ANP could contribute to the obtention of $\mathrm{HCOOH}$, the functionalized GQDs allowed for the increased production of $\mathrm{HCOOH}$ one order of magnitude higher due to the increase in the light absorption ability of the photocatalyst [160].

Carbon-based structures, such as graphitic carbon nitride $\left(\mathrm{g}-\mathrm{C}_{3} \mathrm{~N}_{4}\right)$, have also been functionalized (or decorated) with CDs. Despite its excellent chemical stability and tunable band structure, the photocatalytic activity of $\mathrm{g}-\mathrm{C}_{3} \mathrm{~N}_{4}$ is limited by low $\mathrm{CO}_{2}$ adsorption capacity and high electron-hole recombination rates. Thus, the formation of composites with CDs is an efficient method to promote the separation of photoexcited charge carriers. Ong et al. reported for the first time the construction of the heterojunction photocatalyst made of CDs electrostatically attached to the surface of protonated $g-C_{3} \mathrm{~N}_{4}$. The authors observed a higher than two-fold increase in the obtention of $\mathrm{CH}_{4}$ and $\mathrm{CO}$ when the CDs were present and assigned this observation to the rapid interfacial transfer of the photogenerated electrons from the carbon nitride to the CDs that reduced the electronhole recombination rate [103]. Qian Li et al. prepared oxygen-doped $\mathrm{g}-\mathrm{C}_{3} \mathrm{~N}_{4}$ materials and decorated the surface with $\mathrm{CDs}$, increasing the $\mathrm{CH}_{4}$ production nearly 14 times in comparison with pure g- $\mathrm{C}_{3} \mathrm{~N}_{4}$ [153]. Jo et al. prepared a more complex hybrid system integrating N-CDs, g- $\mathrm{C}_{3} \mathrm{~N}_{4}$, and CoAl layered double hydroxides (LDH) [88]. The increased $\mathrm{CH}_{4}$ production is assigned to the synergistic interaction between the three components. In the particular case of the N-CDs, they contribute to light absorption, electron storage, and $\mathrm{CO}_{2}$ adsorption sites. In contrast to these three papers, You Wang et al. designed $\mathrm{N}-\mathrm{CD}$ able to act as hole scavengers in combination with $\mathrm{g}-\mathrm{C}_{3} \mathrm{~N}_{4}$ with the final objective to promote water oxidation and enhance $\mathrm{CH}_{3} \mathrm{OH}$ production with high selectivity [89]. The N-GQDs, with graphitic structure, were synthesized by the microwave method, and concentrated around the boundaries and edges of the $\mathrm{C}_{3} \mathrm{~N}_{4}$ nanosheets. The composite showed active production of the six-electron product $\mathrm{CH}_{3} \mathrm{OH}$ and oxygen after light irradiation of $\mathrm{CO}_{2}$ in water, which acts as the only electron donor. Consequently, the only oxidation product is $\mathrm{O}_{2}$. The composite was also prepared with $\mathrm{N}-\mathrm{CD}$ s prepared by the solvothermal method with amorphous structure. In this case, the N-CDs acted as electron acceptor producing only the two-electron $\mathrm{CO}$ as a product.

In a further work, You Wang and coworkers combined the same microwave synthesized N-CDs with a carbon nitride-like polymer (FAT) where some terminal $\mathrm{N}$ had been replaced by $\mathrm{O}$ [126]. Contrarily to $\mathrm{g}-\mathrm{C}_{3} \mathrm{~N}_{4}$, FAT mainly traps holes that are extracted by the $\mathrm{N}-\mathrm{CDs}$, located at the interlayers of FAT. N-CDs/FAT composite selectively reduced $\mathrm{CO}_{2}$ to $\mathrm{CH}_{3} \mathrm{OH}$ by water under neutral conditions with $\mathrm{O}_{2}$ as the only oxidation product. The composite's propensity of trapping and selective extraction of holes leads to significant improvement in activity when compared to the reported N-CDs/g- $\mathrm{C}_{3} \mathrm{~N}_{4}$ composite. For instance, no product of $\mathrm{CO}$ from methanol oxidation could be detected. Finally, utilization of N-CDs synthesized at different microwave powers indicated that more crystallized graphite structure is favorable to the photocatalytic performance of N-CDs.

Liu et al. addressed the comparison of photocatalytic activity between amorphous CDs and graphitized GQDs as well. The authors claimed that the presence of defined and big $\mathrm{sp}^{2}$ domains are responsible for the efficient separation of the photogenerated electron and hole pairs [46]. Nitrogen functionalization favored the hole scavenging, creating electron accumulation sites on the $\mathrm{sp}^{2}$ domains in the surface that would act as electroactive sites for the $\mathrm{CO}_{2}$ reduction. In addition, the surface nitrogen-containing groups induced stronger chemisorption properties of the intermediates that led to higher selectivity towards $\mathrm{CH}_{4}$.

With a similar approach, Yan et al. raised the hypothesis that the presence of intramolecular combination of $\mathrm{p}$ - and $\mathrm{n}$-type domains separated by $\mathrm{sp}^{2}$-carbon ohmic contacts in GQDs favors charge separation. Moreover, if the values of the conduction band (CB) and the valence band (VB) were compatible with the standard redox potentials for water splitting or $\mathrm{CO}_{2}$ reduction in water, the GQDs would be able to photocatalyze these reactions. Consequently, the authors methodically tuned the band gap values of the GQDs to determine their potential activity in water splitting and $\mathrm{CO}_{2}$ reduction. The band 
gap tailoring was achieved by functionalization with polyaromatic rings to enlarge the $\pi$-conjugated $\mathrm{sp}^{2}$-carbon network or with electron donating groups to narrow the band gap [44] (see Figure 4). The GQDs functionalized with 1,1'-bi(2-naphthalene) (BNPTL) had the narrower band gap and the highest $\mathrm{H}_{2}$ yield of all the series, even higher than previously reported GQDs containing systems. The same compound also showed the highest rate for $\mathrm{CO}_{2}$ conversion to $\mathrm{CH}_{3} \mathrm{OH}$. The enhanced light absorption, in comparison to the other molecules, and the charge separation ability were responsible for this demonstration of the GQDs potential.

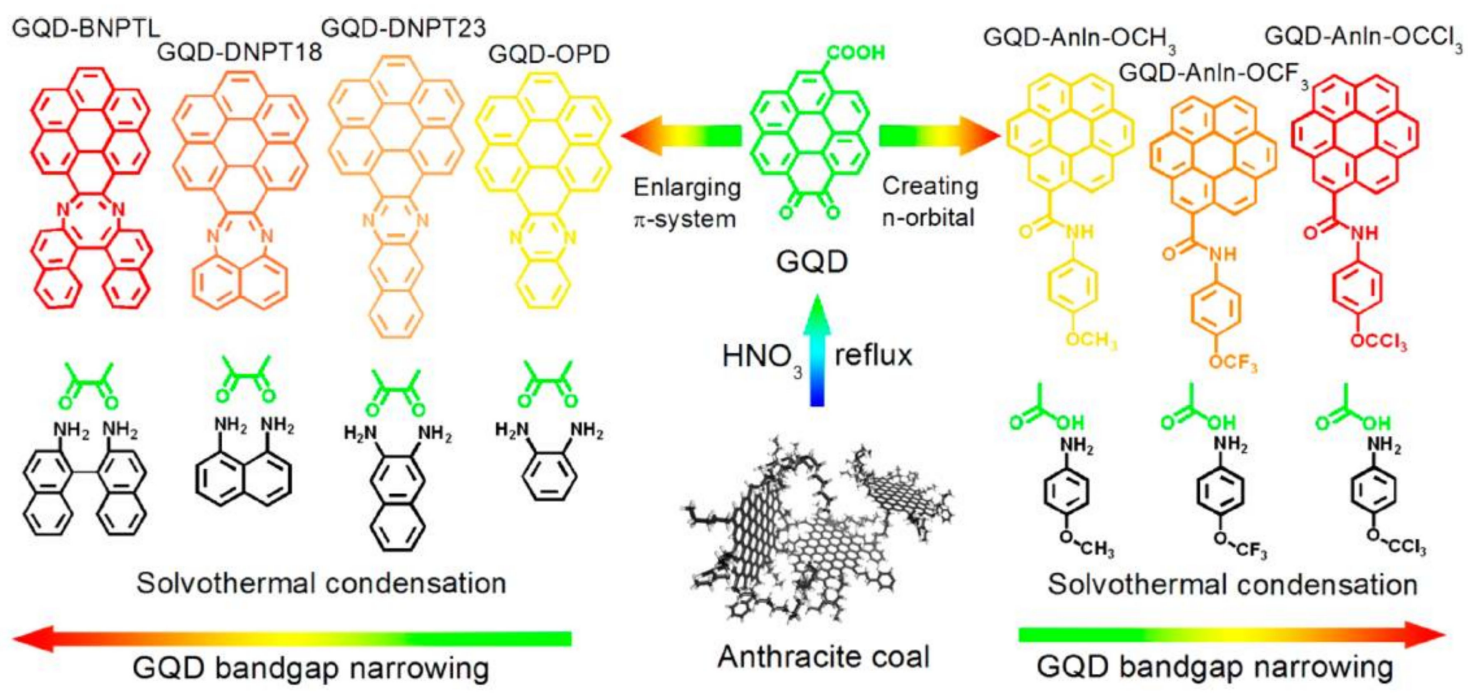

Figure 4. Schematic illustration of the strategies for band gap narrowing by enlarging the $\pi$ conjugated system or by introducing intermediate n-orbitals. Reprinted with permission from reference [44]. Copyright 2018 American Chemical Society.

\subsection{Metal/Transition Metal-Based Hybrids and Composites}

As mentioned before, Cao et al. reported in 2011 the application of gold or platinum functionalized nanoscale carbon-based structures for $\mathrm{CO}_{2}$ reduction in water solution, yielding $\mathrm{HCOOH}$ [107]. This primary study was later revisited and validated in 2014 by the same authors [161], who optimized the synthesis of the CDs and covered the surface with gold. The exposure of the system to light irradiation induced charge separation in the CDs and the subsequent electron harvesting by the gold dopant on the surface. The electron accumulation on the metal favored the creation of photocatalytic activation sites that, in combination with pressurized $\mathrm{CO}_{2}$ and the use of isopropanol as sacrificial electron donor, was responsible for the formation of acetic acid. It is worth mentioning that the yield of $\mathrm{HCOOH}$ increased along with the increasing pressure of $\mathrm{CO}_{2}$, suggesting the role of the $\mathrm{CO}_{2}$ concentration in the harvesting of photogenerated electrons in CDs.

CDs have also been combined with other successful visible-light driven photocatalysts, such as $\mathrm{Cu}_{2} \mathrm{O}$. The addition of the CDs increased the stability and the light absorption ability of the composite. In this case, the CDs acted as acceptors of the photogenerated holes and were responsible for the oxidation of $\mathrm{H}_{2} \mathrm{O}$ to $\mathrm{O}_{2}$ [105]. This approach was later enhanced by adding a carbon layer on top of the CDs to protect the semiconductor from light irradiation, increase light absorption by increasing the light reflection while acting as electron transfer layer between $\mathrm{Cu}_{2} \mathrm{O}$ and the CDs. As a consequence, the photocatalytic conversion of $\mathrm{CO}_{2}$ in water resulted in higher rates of $\mathrm{CH}_{3} \mathrm{OH}$ production with higher selectivity [104]. 
The combination of CDs with the popular $\mathrm{TiO}_{2}$ has been reported by Mengli Li et al. In the paper, the authors used CDs to expand the light absorption range of $\mathrm{TiO}_{2}$ which is otherwise limited to the UV part of the solar light irradiation [72]. To further enhance the photocatalytic activity of the system, the authors synthesized N,S-CDs with thiourea in order to functionalize the surface of the CDs with $\mathrm{N}, \mathrm{O}$, and S-containing groups. In the presence of $\mathrm{CO}_{2}$ and light irradiation, the N,S-CDs absorbed light in the visible and NIR regions and acted as electron reservoir accepting the photoinduced electrons transferred from the $\mathrm{TiO}_{2}$. The accumulated electrons reduced the $\mathrm{CO}_{2}$ molecules in solution to $\mathrm{CO}$ and $\mathrm{CH}_{4}$.

Zhong et al. reported a more complex system formed by a COF hosting a nickel porphyrin-based carbon dot (Ni-PCD@TD-COF). This was the first example in which a molecular catalyst was introduced in the porous COF network for photocatalytic $\mathrm{CO}_{2}$ reduction [78]. The organic framework provided higher adsorption capacity and selectivity towards $\mathrm{CO}_{2}$ than other semiconductors, whereas avoided the leaching of the metalloporphyrin molecule that is responsible for the catalytic activity. The CDs, in turn, provided stable active sites for the $\mathrm{CO}_{2}$ reduction. In combination with the photosensitizer $\left[\mathrm{Ru}(\mathrm{bpy})_{3}\right] \mathrm{Cl}_{2}$, and the triethanolamine (TEOA) which was the sacrificial reductant, the Ni-PCD@TD-COF system achieved 98\% selectivity in the $\mathrm{CO}_{2}$-to-CO conversion over $\mathrm{H}_{2}$ generation.

\section{Electrocatalytic $\mathrm{CO}_{2}$ Reduction}

\subsection{Metal-Free Catalysts}

Due to their low cost, high conductivity, and surface area, non-metallic heteroatomdoped (e.g., N, S, B) carbon materials have attracted some interest as potential electrocatalysts for $\mathrm{CO}_{2} \mathrm{RR}[162,163]$. Recently, polyacrylonitrile-based carbon nanofibers were found to catalyze $\mathrm{CO}_{2}$ conversion to $\mathrm{CO}$ with high faradaic efficiency (FE) in an ionic liquid electrolyte [164]. N-doped carbon nanotubes (CNTs) were also reported as effective catalysts for electrochemical $\mathrm{CO}_{2}$ activation and conversion in aqueous media, with preferential $\mathrm{CO}[165,166]$ or $\mathrm{HCOO}^{-}$[167] formation apparently depending on the synthetic conditions and the chemical composition. For instance, N-doped CNT/glassy carbon (GC) electrodes obtained by ammonia plasma treatment provided a 59\% $\mathrm{FE}$ for $\mathrm{HCOO}^{-}$production in $0.1 \mathrm{M} \mathrm{KHCO}_{3}$ electrolyte, which increased to $85 \%$ upon polymer functionalization with polyethylenimine (PEI) [167]. On the other hand, $\mathrm{CO}$ was found to be the major $\mathrm{CO}_{2} \mathrm{RR}$ product formed by other $\mathrm{N}$-doped CNTs synthesized using different nitrogen-containing precursors, whereby the presence of graphitic and pyridinic $\mathrm{N}$ defects was proposed to be key to improve $\mathrm{CO}_{2} \mathrm{RR}$ performances and $\mathrm{CO}$ selectivity [166]. In a similar fashion, $\mathrm{N}$-doped graphene metal-free catalysts have been recently reported to convert $\mathrm{CO}_{2}$ to either $\mathrm{CO}[168,169]$ or $\mathrm{HCOO}^{-}$[170] with high FEs, whereas boron (B)-doped graphene displayed good selectivity towards catalytic $\mathrm{HCOO}^{-}$formation [171] (Table 2). Moreover, a series of metal-free carbon materials have been recently reported to efficiently catalyze $\mathrm{CO}_{2}$ electroreduction to further reduced products, such as acetate $\left(\mathrm{CH}_{3} \mathrm{COO}^{-}\right)$[172], ethanol $\left(\mathrm{C}_{2} \mathrm{H}_{5} \mathrm{OH}\right)[173,174]$, or methane $\left(\mathrm{CH}_{4}\right)[175]$, in aqueous electrolytes (Table 2).

By combining heteroatom $\mathrm{N}$-doping and high density of reactive edge sites, N-GQDs featured unique electrocatalytic $\mathrm{CO}_{2} \mathrm{RR}$ properties. In a flow cell reactor and alkaline electrolyte (1 M KOH), N-GQDs deposited on a gas diffusion layer (GDL) electrode displayed a primary conversion of $\mathrm{CO}_{2}$ into $\mathrm{CO}$ and $\mathrm{HCOO}^{-}$at relatively low overpotentials, while promoting the formation of multi-electron $\mathrm{CO}_{2} \mathrm{RR}$ products at more cathodic potentials, including $\mathrm{CH}_{4}$ (maximum $\mathrm{FE}=15 \%$ at $-0.86 \mathrm{~V}$ vs. $\mathrm{RHE}$ ), as well as multi-carbon $\left(\mathrm{C}_{\geq 2}\right)$ hydrocarbons and oxygenates (Table 2) [17]. In particular, $\mathrm{C}_{2} \mathrm{H}_{4}$ was found to be the major hydrocarbon product with a maximum FE of $31 \%$ at $-0.75 \mathrm{~V}$ vs. RHE, whereas a maximum overall $\mathrm{FE}=26 \%$ was obtained for multi-carbon oxygenates at $-0.78 \mathrm{~V}$ vs. $\mathrm{RHE}\left(\mathrm{C}_{2} \mathrm{H}_{5} \mathrm{OH}\right.$ resulting the major component, $\mathrm{FE}_{\mathrm{C} 2 \mathrm{H} 5 \mathrm{OH}}=16 \%$ ), thus providing comparable results to previously reported $\mathrm{Cu}$-based nanostructured catalysts (Figure $5 \mathrm{a}, \mathrm{b}$ ) $[17,176]$. In comparison with N-GQDs, pristine GQDs only produced $\mathrm{CO} / \mathrm{HCOO}^{-}$mixtures with lower FEs to- 
gether with only traces of $\mathrm{CH}_{4} / \mathrm{C}_{2} \mathrm{H}_{4}$ and no detectable amounts of oxygenates, suggesting the critical role of nitrogen moieties incorporated into the conjugated carbon nanostructure (Figure 5c,d). Furthermore, noticeable amounts of hydrocarbons and oxygenates were also detected on control micro-sized N-doped reduced graphene oxide (N-RGO), albeit at a considerably higher overpotential than N-GQDs, thus highlighting the importance of the nanoscale morphology for the optimization of the $\mathrm{CO}_{2} \mathrm{RR}$ performances. It was proposed that the enriched pyridinic $\mathrm{N}$ doping at the exposed edge sites is at the origin of the outstanding activity and selectivity towards $C_{\geq 2}$ hydrocarbons and oxygenates observed for N-GQDs [17,176]. In a follow-up work, first-principles calculations were used to provide theoretical insights into the possible pathways for $\mathrm{CO}_{2} \mathrm{RR}$ catalyzed by N-GQDs and to rationalize the experimentally observed selectivity [177]. The ${ }^{*} \mathrm{COOH}$ binding step (* indicates the adsorption site), crucial for the initial two-electron reduction of $\mathrm{CO}_{2}$ to $\mathrm{CO}$, was predicted to be energetically more favorable in the presence of $\mathrm{N}$-doped edges compared to $\mathrm{N}$-doped graphene. Moreover, the preferential formation of $\mathrm{CH}_{4}$ over $\mathrm{CH}_{3} \mathrm{OH}$ was proposed to originate from the decreased kinetic barrier for the step leading to the key ${ }^{*} \mathrm{CH}_{2}$ intermediate from ${ }^{*} \mathrm{CH}_{2} \mathrm{OH}$ assisted by $\mathrm{H}_{2} \mathrm{O}$ molecules, which enable a more favorable $\mathrm{H}$ shuttling pathway for the dissociation process [177]. On the other hand, the formation of $\mathrm{C}_{\geq 2}$ hydrocarbons and oxygenates is primarily determined by the subsequent coupling of ${ }^{*} \mathrm{CH}_{2}$ and $\mathrm{CO}$ to form the ${ }^{*} \mathrm{CH}_{2} \mathrm{CO}$ intermediate, engaging the pyridine $\mathrm{N}$ site and the nearest-neighbor zig-zag edge $C$ atom [177], in sharp contrast with the main pathway commonly reported for $\mathrm{C}-\mathrm{C}$ bond formation by $\mathrm{Cu}$ catalysts which involves $\mathrm{CO}$ dimerization step [178].

a
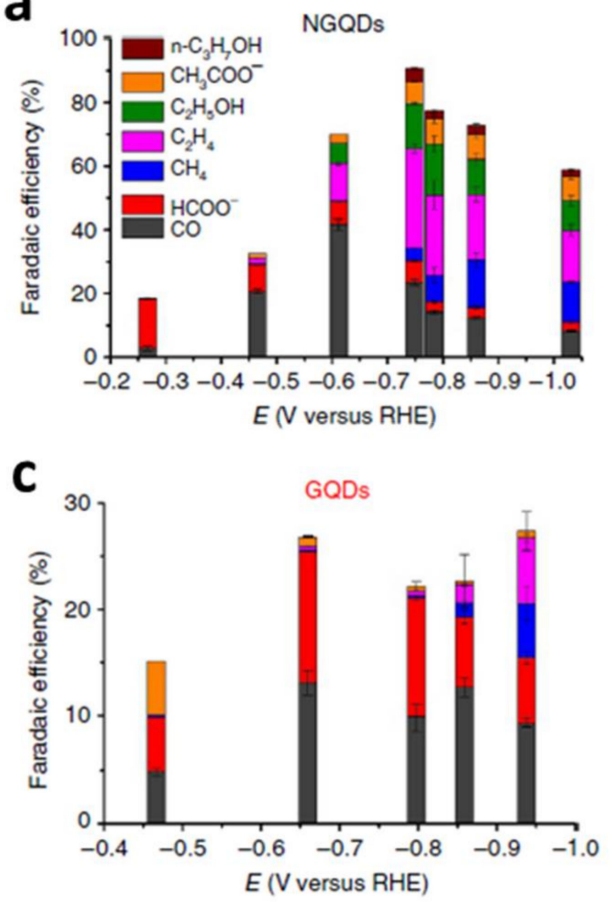

b

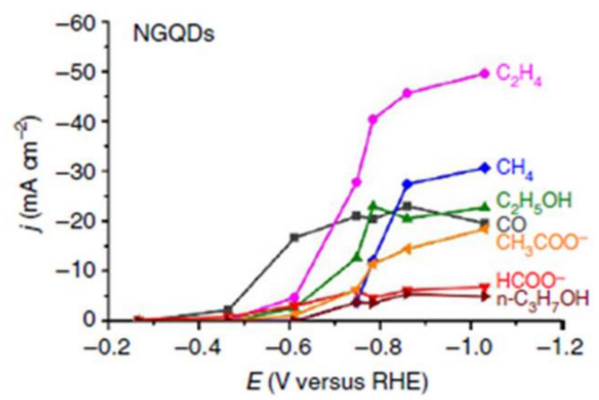

d

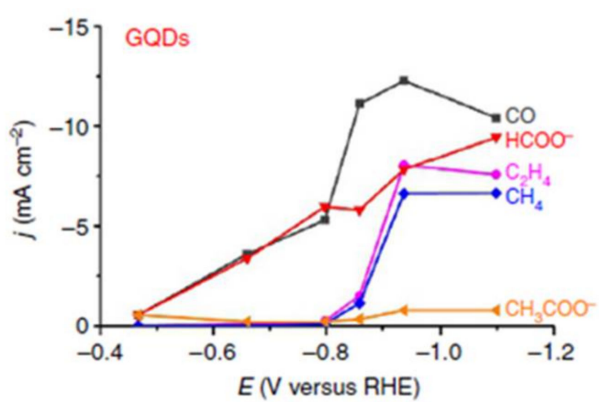

Figure 5. Electrocatalytic $\mathrm{CO}_{2} \mathrm{RR}$ activity of N-GQDs $(\mathbf{a}, \mathbf{b})$ and pristine GQDs (c,d) deposited on gas-diffusion electrodes in a flow cell in $1 \mathrm{M} \mathrm{KOH}$ electrolyte. Faradaic efficiencies (FEs, (a-c)) and partial current densities $(\mathrm{j},(\mathbf{b}-\mathbf{d}))$ for $\mathrm{CO}_{2}$ reduction toward the formation of various products $(\mathrm{CO}$, $\mathrm{CH}_{4}, \mathrm{C}_{2} \mathrm{H}_{4}, \mathrm{HCOO}^{-}, \mathrm{C}_{2} \mathrm{H}_{5} \mathrm{OH}, \mathrm{CH}_{3} \mathrm{COO}^{-}$, and $\left.n-\mathrm{C}_{3} \mathrm{H}_{7} \mathrm{OH}\right)$ at various applied cathodic potentials. Adapted with permission from reference [17]. Copyright 2016, Nature Publishing Group. 
Table 2. Electrocatalytic $\mathrm{CO}_{2} \mathrm{RR}$ performances reported for selected systems based on carbon dots and on other metal-free carbon materials.

\begin{tabular}{|c|c|c|c|}
\hline Catalyst & Electrolyte & Major Product(s) (FE, \%) & Applied Potential (vs. RHE) \\
\hline $\begin{array}{c}\text { N-doped 3D graphene foam } \\
\text { [169] }\end{array}$ & $0.1 \mathrm{M} \mathrm{KHCO}_{3}$ & $\mathrm{CO}(85 \%)$ & $-0.58 \mathrm{~V}$ \\
\hline N-doped graphene [170] & $0.5 \mathrm{M} \mathrm{KHCO}_{3}$ & $\mathrm{HCOO}^{-}(73 \%)$ & $-0.84 \mathrm{~V}$ \\
\hline $\begin{array}{l}\text { N-doped nanodiamond/Si } \\
\text { rod array (NDD/Si RA) [172] }\end{array}$ & $0.5 \mathrm{M} \mathrm{NaHCO}_{3}$ & $\mathrm{CH}_{3} \mathrm{COO}^{-}(77.3-77.6 \%)$ & $-0.8 \mathrm{~V} /-1.0 \mathrm{~V}$ \\
\hline $\begin{array}{l}\text { Perfluorinated covalent } \\
\text { triazine framework } \\
\text { (CTF) [175] }\end{array}$ & $0.1 \mathrm{M} \mathrm{KHCO}_{3}$ & $\mathrm{CH}_{4}(99.3 \%)$ & $-0.7 \mathrm{~V} /-0.9 \mathrm{~V}$ \\
\hline $\begin{array}{l}\text { N-doped cylindrical } \\
\text { mesoporous carbon [173] }\end{array}$ & $0.1 \mathrm{M} \mathrm{KHCO}_{3}$ & $\mathrm{CH}_{3} \mathrm{CH}_{2} \mathrm{OH}(77 \%)$ & $-0.56 \mathrm{~V}$ \\
\hline $\begin{array}{c}\text { B-/N-co-doped } \\
\text { nanodiamond [174] }\end{array}$ & $0.1 \mathrm{M} \mathrm{NaHCO}_{3}$ & $\mathrm{CH}_{3} \mathrm{CH}_{2} \mathrm{OH}(93.2 \%)$ & $-1.0 \mathrm{~V}$ \\
\hline \multirow{2}{*}{ N-GQDs [17] } & \multirow{2}{*}{$1 \mathrm{M} \mathrm{KOH}$} & $\mathrm{CH}_{4}(15 \%)$ & $-0.86 \mathrm{~V}$ \\
\hline & & $\mathrm{C}_{2} \mathrm{H}_{4}(31 \%)$ & $-0.75 \mathrm{~V}$ \\
\hline $\begin{array}{c}\mathrm{NH}_{2} \text {-functionalized GQDs } \\
{[100]}\end{array}$ & $1 \mathrm{M} \mathrm{KOH}$ & $\mathrm{CH}_{4}(70.0 \%)$ & $-0.95 \mathrm{~V}$ \\
\hline $\mathrm{Ni}_{1}-\mathrm{N} / \mathrm{CNT}[47]$ & $0.1 \mathrm{M} \mathrm{KHCO}_{3}$ & $\mathrm{CO}(99 \%)$ & $-0.75 \mathrm{~V}$ \\
\hline Cu-CDs [144] & $0.5 \mathrm{M} \mathrm{KHCO}_{3}$ & $\mathrm{CH}_{4}(78 \%)$ & $-1.44 \mathrm{~V}$ \\
\hline porous Ag/CDs [106] & $0.5 \mathrm{M} \mathrm{KHCO}_{3}$ & $\mathrm{CO}(83.2 \%)$ & $-0.8 \mathrm{~V}$ \\
\hline Au NPs/N-GQDs [97] & $0.5 \mathrm{M} \mathrm{KHCO}_{3}$ & $\mathrm{CO}(93 \%)$ & $-0.25 \mathrm{~V}$ \\
\hline $\mathrm{Bi}_{2} \mathrm{O}_{3}-\mathrm{N}-\mathrm{GQDs}$ [99] & $0.5 \mathrm{M} \mathrm{KHCO}_{3}$ & $\mathrm{HCOO}^{-}(98.1 \%)$ & $-0.9 \mathrm{~V}$ \\
\hline $\mathrm{MoS}_{2} / \mathrm{N}-\mathrm{CDs}[154]$ & EMIM-BF $_{4}\left(94 \mathrm{~mol}^{2} \text { water }\right)^{1}$ & $\mathrm{CO}(90.2 \%)$ & $-0.9 \mathrm{~V}$ \\
\hline $\mathrm{Co}_{3} \mathrm{O}_{4}-\mathrm{CDs}-\mathrm{C}_{3} \mathrm{~N}_{4}[51]$ & $0.5 \mathrm{M} \mathrm{KHCO}_{3}$ & $\mathrm{CO}(89 \%)$ & $-0.6 \mathrm{~V}$ \\
\hline $\mathrm{Au}-\mathrm{CDs}-\mathrm{C}_{3} \mathrm{~N}_{4}[50]$ & $0.5 \mathrm{M} \mathrm{KHCO}_{3}$ & $\mathrm{CO}(79.8 \%)$ & $-0.5 \mathrm{~V}$ \\
\hline Cu-GQDs nanocorals [52] & $0.5 \mathrm{M} \mathrm{KHCO}_{3}$ & $\begin{array}{l}\mathrm{HCOO}^{-}(68 \%) \\
\mathrm{CH}_{3} \mathrm{OH}(11 \%)\end{array}$ & $-0.7 \mathrm{~V}$ \\
\hline N-GQDs /Cu-nr [59] & $1 \mathrm{M} \mathrm{KOH}$ & $\begin{array}{l}\mathrm{C}_{\geq 2} \text { products }(80.4 \%) \\
\mathrm{C}_{\geq 2} \text { alcohols }(52.4 \%)\end{array}$ & $-0.9 \mathrm{~V}$ \\
\hline
\end{tabular}

${ }^{1} \mathrm{EMIM}^{-\mathrm{BF}_{4}}=1$-Ethyl-3-methylimidazolium Tetrafluoroborate.

Surface functionalization was recently revealed to be an effective strategy to tune the catalytic activity and selectivity of GQDs towards the formation of specific $\mathrm{CO}_{2} \mathrm{RR}$ products, by altering the electronic structure of the catalyst, as well as the adsorption energy of key surface-bound intermediates. In particular, GQDs featuring varying contents of specific functional groups on their surface were systematically investigated for $\mathrm{CO}_{2} \mathrm{RR}$, allowing to correlate the catalytic performances with the electronic properties of the substituents [100]. As a general trend, the presence of electron-withdrawing groups onto GQDs (e.g., - $\mathrm{COOH}$, $-\mathrm{SO}_{3}$ ) tend to suppress $\mathrm{CO}_{2} \mathrm{RR}$ favoring HER. Contrariwise, GQDs decorated with electrondonating functional groups (e.g., $-\mathrm{OH},-\mathrm{NH}_{2}$ ) were found to enhance $\mathrm{CO}_{2} \mathrm{RR}$ selectivity towards $\mathrm{CH}_{4}$ formation. Such a boosting effect was found to be even more pronounced for GQDs enriched with $\mathrm{NH}_{2}$ functionalities, leading to maximum $\mathrm{FE}$ and partial current density of $70.0 \%$ and $-200 \mathrm{~mA} \mathrm{~cm}^{-2}$ for $\mathrm{CH}_{4}$ production, respectively [100]. In agreement with these findings, an in situ amine functionalization strategy of N-CDs which ensured a better control over the total and the specific $\mathrm{N}$ active sites incorporated into the carbon nanostructure, led to a significant improvement of the $\mathrm{CO}_{2}$-to- $\mathrm{CH}_{4}$ performances [90]. The total $\mathrm{N}$ atomic content in the N-GQDs was found to positively impact the overall $\mathrm{CO}_{2} \mathrm{RR}$ performances, whereas the catalytic selectivity was dependent on the specific type of $\mathrm{N}$ 
configurations. The FE and production rate for $\mathrm{CH}_{4}$ and $\mathrm{C}_{2}$ products displayed a linear correlation with the content of $-\mathrm{NH}_{2}$ and pyridinic $\mathrm{N}$ dopants, respectively, whereas any specific relationships with $\mathrm{CO}_{2} \mathrm{RR}$ selectivity toward a certain product were obtained for pyrrolic $\mathrm{N}$, graphitic $\mathrm{N}$, and nitrogen oxide functionalities [90].

\subsection{Transition Metal-Based Single-Atom Catalysts}

In the last years, metal-doped graphene quantum dots (M-GQDs) have been explored as suitable precursors to obtain atomically dispersed transition metal-based single atom catalysts (SACs) for an efficient and selective $\mathrm{CO}_{2} \mathrm{RR}$ in aqueous electrolytes $[47,101]$. For instance, a versatile GQD-tethering strategy for SACs synthesis was recently developed by Jin et al., consisting in an initial metal ion complexation into a GQD to form a stable coordination M-GQD adduct, which is then assembled on CNT support via $\pi-\pi$ interactions (Figure 6a) [47]. Ultimately, the hybrid M-GQD/CNT material undergoes high-temperature annealing under $\mathrm{NH}_{3}$ / Ar leading to uniformly distributed $\mathrm{M}-\mathrm{N}_{\mathrm{x}}$ moieties on a conductive carbon support. In comparison with the traditional top-down and bottom-up methods for SACs synthesis [179], this approach takes advantage of the stable metal-GQD interaction which prevents agglomeration of metal atoms during the pyrolysis treatment. Furthermore, the abundance of oxygenated functional groups and defective sites on the surface of GQDs increases their capability of anchoring metal ions, resulting in SACs with considerably higher metal loadings compared to those obtained by more conventional methods. Following this approach, a series of SACs containing different transition metal atoms (including $\mathrm{Cr}, \mathrm{Mn}, \mathrm{Fe}, \mathrm{Co}, \mathrm{Ni}, \mathrm{Cu}, \mathrm{Zn}$ ) with metal loading between 3.0 and $4.5 \%$ wt. were successfully synthesized and tested for $\mathrm{CO}_{2} \mathrm{RR}$ in $0.1 \mathrm{M} \mathrm{KHCO}_{3}$ electrolyte [47]. Among them, the $\mathrm{Ni}_{1}$ $\mathrm{N} / \mathrm{CNT}$ catalyst exhibited excellent selectivity and durability for $\mathrm{CO}_{2}$-to-CO conversion, achieving a maximum $\mathrm{FE}_{\mathrm{CO}}=99 \%$ at $-0.75 \mathrm{~V}$ vs. RHE (Figure $6 \mathrm{~b}$ ) and maintaining an almost quantitative FE for CO production over $60 \mathrm{~h}$ operation [47]. More recently, an analogous synthetic method based on the use of strongly chelating amine-functionalized GQDs as precursors for metal atom trapping enabled to obtain SACs with different transition metals possessing further increased metal loadings up to a record value of ca. $40 \% \mathrm{wt}$. [101]. For example, the atomically dispersed Ni-N-C-3 catalyst displayed a metal loading of approximately $15 \% \mathrm{wt}$., considerably higher than the values commonly reported for $\mathrm{Ni}$ SACs [180,181], providing outstanding $\mathrm{CO}_{2} \mathrm{RR}$ performances for selective $\mathrm{CO}$ production (>90\% selectivity and a ca. $122 \mathrm{~mA} \mathrm{~cm}^{-2}$ partial current density) at a cell voltage of ca. $2.55 \mathrm{~V}$ in a flow electrochemical cell [101].

In some cases, high annealing temperatures are not required to obtain carbon dotsbased SACs for efficient $\mathrm{CO}_{2} \mathrm{RR}$. Recently, mild-temperature calcination of the organometallic $\mathrm{Na}_{2}[\mathrm{Cu}(\mathrm{EDTA})]$ complex ultimately led to the formation of a CDs-supported SAC containing well-defined $\mathrm{CuN}_{2} \mathrm{O}_{2}$ moieties, reminiscent of the original metal atom coordinative sites of the molecular precursor (Figure 6c) [144]. The resulting Cu-CDs material displayed unique catalytic $\mathrm{CO}_{2} \mathrm{RR}$ properties, with extremely high FEs (maximum $\mathrm{FE}_{\mathrm{CH} 4}$ $\sim 78 \%$ at $-1.44 \mathrm{~V}$ vs. $\mathrm{RHE})$ and selectivity toward $\mathrm{CH}_{4}$ formation $\left(>99 \%\right.$ of the $\mathrm{CO}_{2} \mathrm{RR}$ products) (Figure 6d), outperforming the reference CuPc catalysts in terms either $\mathrm{CH}_{4}$ selectivity and catalyst stability. Both experimental and theoretical investigation highlighted the pivotal role of the $\mathrm{CuN}_{2} \mathrm{O}_{2}$ sites on the unusually high observed catalytic $\mathrm{CH}_{4}$ selectivity [144]. 
a

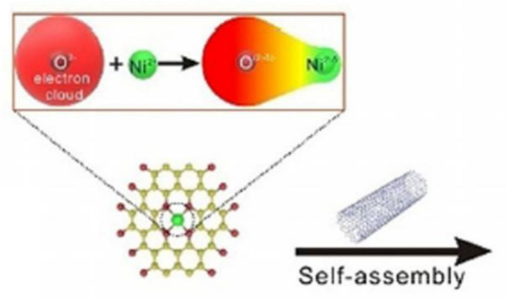

GQD-Ni complex
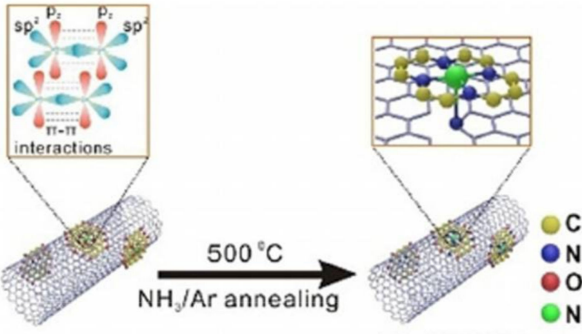

$\mathrm{Ni}_{1}-\mathrm{N} / \mathrm{CNT}$ b

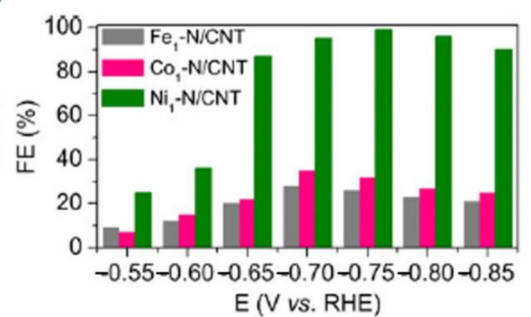

d

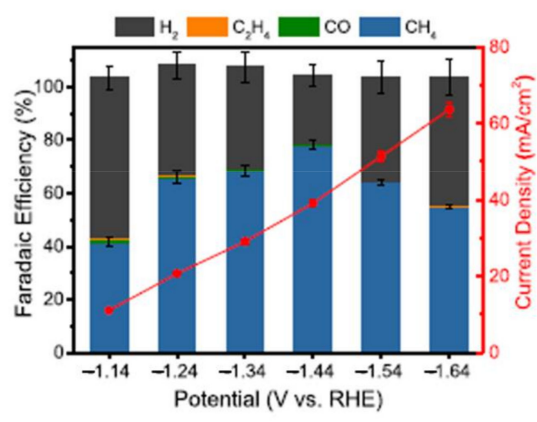

C

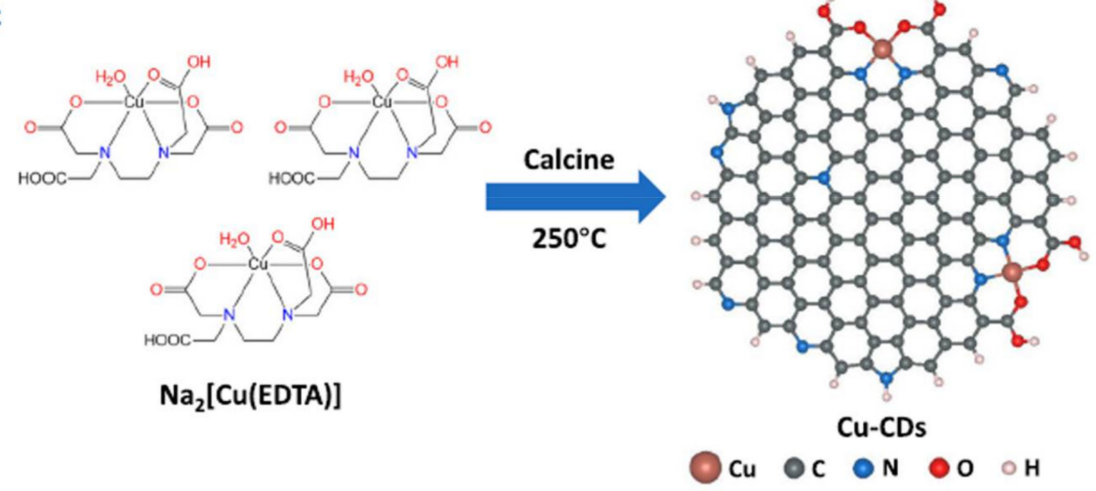

Figure 6. (a,b) Illustration of the preparation of $\mathrm{M}_{1}-\mathrm{N} / \mathrm{CNT}$ SACs $(\mathrm{M}=\mathrm{Fe}, \mathrm{Co}, \mathrm{Ni})(\mathbf{a})$ and their observed FEs for $\mathrm{CO}_{2} \mathrm{RR}$ to $\mathrm{CO}$ at various applied potentials (b). Adapted with permission from reference [47]. Copyright 2020, Wiley-VCH. (c,d) Scheme of the low-temperature calcining procedure for $\mathrm{Cu}$-CDs catalyst (c) and dependence of FE (left y-axis) and current density (based on geometric surface area, right y-axis) of Cu-CDs (d). Adapted with permission from reference [144] Copyright 2021, Nature Publishing Group.

\subsection{Metal/Metal-Oxide Composites}

CDs can be also used in combination with catalytically active metal or metal-oxide nanostructured materials, leading to hybrid catalysts with improved electrocatalytic $\mathrm{CO}_{2} \mathrm{RR}$ performances. In these composite catalysts, the presence of CDs may enable the tuning of $\mathrm{CO}_{2} \mathrm{RR}$ selectivity toward specific products or boost their intrinsic activity, acting as a co-catalyst component or providing additional catalytic active sites. Two-electron $\mathrm{CO}_{2}$ reduction products, such as $\mathrm{CO}$ and formate, are the most commonly products formed by metallic heterogeneous catalysts, although selectivity is still a major challenge, especially in aqueous electrolytes. Noble metals, such as Ag [182-184] and Au [185-187], are the most widely studied transition metals for selective $\mathrm{CO}$ production due to their favorable energies for CO desorption [188,189], whereas a few examples of other metals, such as $\mathrm{Pb}[190]$, $\mathrm{Sn}$ [191], and Bi [192], have been reported to catalyze $\mathrm{HCOO}^{-}$production with relatively high faradaic yields. In general, the hybridization of nanostructured metal catalysts with $\mathrm{CDs}$ has been demonstrated to be beneficial for the $\mathrm{CO}_{2} \mathrm{RR}$ catalytic performances. For instance, a porous $\mathrm{Ag} / \mathrm{CDs}$ composite catalyst was found to selectively reduce $\mathrm{CO}_{2}$ to $\mathrm{CO}$ with a maximum FE of $83.2 \%$ at $-0.8 \mathrm{~V}$ vs. RHE, outperforming both the control polycrystalline Ag foil and the CD-free porous Ag samples in terms of onset potential required for $\mathrm{CO}_{2}$ conversion to $\mathrm{CO}$ and $\mathrm{CO}$ selectivity (Figure 7a) [106]. Although the CDs alone displayed predominant HER activity, they were found to positively impact the capability of $\mathrm{CO}_{2}$ adsorption and $\mathrm{CO}$ desorption on porous $\mathrm{Ag}$, leading to the experimentally observed catalytic improvement of $\mathrm{CO}_{2}$ RR-to-CO properties of the material. In a similar fashion, single-crystalline Au NPs wrapped by N-CDs served as highly active and CO-selective electrocatalyst, being capable of catalytically converting $\mathrm{CO}_{2}$ to $\mathrm{CO}$ at a considerably lower overpotential compared to the CDs-free Au NPs, as well as sustaining high $\mathrm{FE}_{\mathrm{CO}}$ values in a wide potential range $(-0.25 \mathrm{~V}$ and $-0.65 \mathrm{~V}$ vs. RHE) [97]. It was proposed that a synergistic effect between the two components is responsible for an improved ${ }^{*} \mathrm{COOH}$ 
binding on pyridinic $\mathrm{N}$ sites of the composite catalyst, which ultimately results in enhanced $\mathrm{CO}_{2} \mathrm{RR}$ performances. Following an analogous approach, the combination of nanostructured $\mathrm{Bi}_{2} \mathrm{O}_{3}$ or $\mathrm{SnO}_{2}$ materials and N-CDs led to highly active composite catalysts for selective $\mathrm{HCOO}^{-}$formation in aqueous electrolyte (FE $>90 \%$ between $-0.9 \mathrm{~V}$ and $-1.2 \mathrm{~V}$ vs. RHE for $\mathrm{Bi}_{2} \mathrm{O}_{3} / \mathrm{N}-\mathrm{CD}$ catalyst) (Figure 7b) [99].
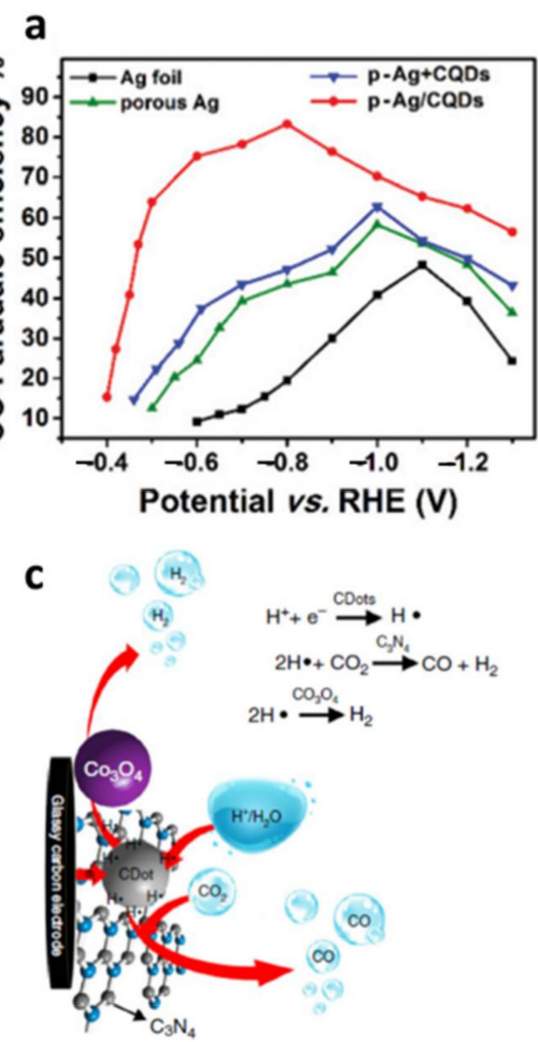

e

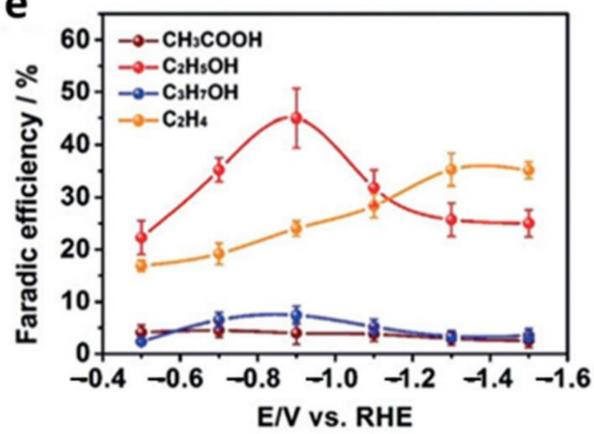

b

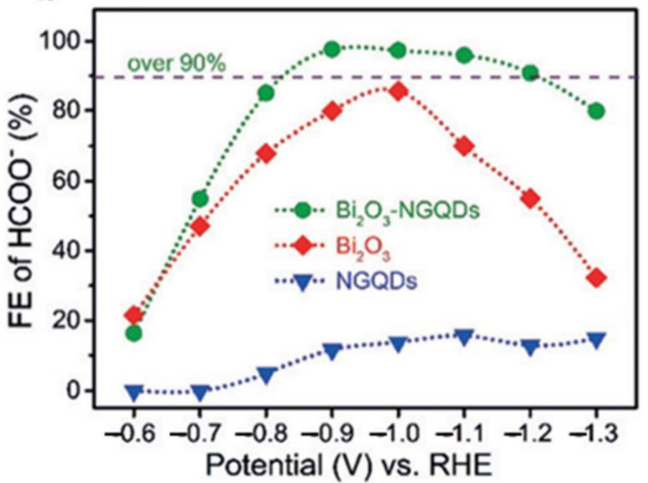

d

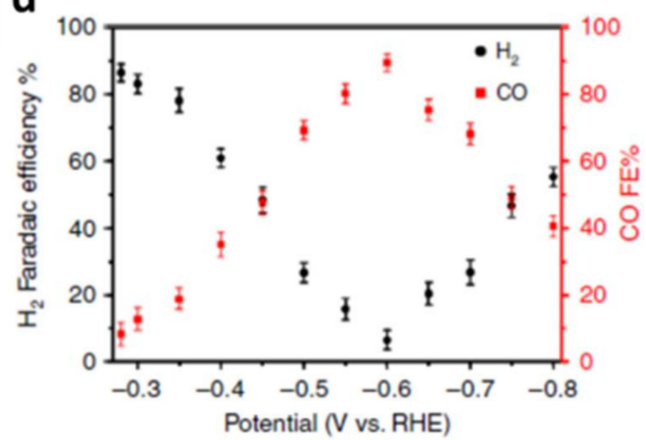

f

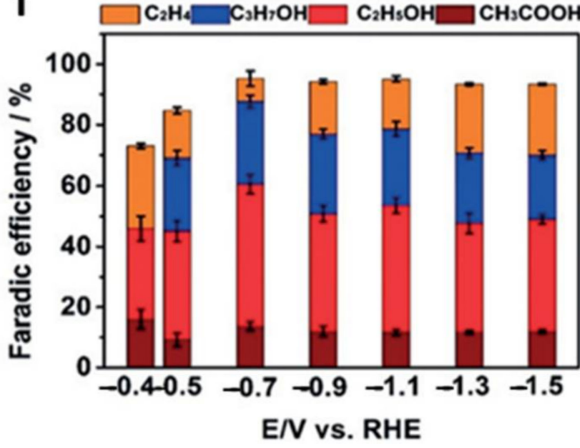

Figure 7. (a) $\mathrm{FE}_{\mathrm{CO}}$ vs. the applied potential of $\mathrm{CD}$-covered porous $\mathrm{Ag}$ (p-Ag/CDs) in $\mathrm{CO}_{2}$-saturated $0.5 \mathrm{M} \mathrm{KHCO}_{3}$ electrolyte. Adapted with permission from reference [106]. Copyright 2019, Royal Society of Chemistry. (b) FE of $\mathrm{HCOO}^{-}$production on $\mathrm{Bi}_{2} \mathrm{O}_{3}-\mathrm{N}-\mathrm{GQDs}, \mathrm{Bi}_{2} \mathrm{O}_{3}$ and N-GQDs at different electrolytic potentials. Adapted with permission from reference [99]. Copyright 2018, Wiley-VCH. (c) Schematic diagram of the reaction mechanism induced by $\mathrm{Co}_{3} \mathrm{O}_{4}-\mathrm{CDs}_{-} \mathrm{C}_{3} \mathrm{~N}_{4}$. CDs are the generation site of $\mathrm{H}^{\bullet}, \mathrm{Co}_{3} \mathrm{O}_{4}$ the generation site of $\mathrm{H}_{2}$, and $\mathrm{C}_{3} \mathrm{~N}_{4}$ the generation site of CO. (d) FEs of the reduction of $\mathrm{CO}_{2}$ to $\mathrm{CO}$ (red points) and $\mathrm{H}^{+}$to $\mathrm{H}_{2}$ (black points) catalyzed by $\mathrm{Co}_{3} \mathrm{O}_{4}-\mathrm{CDs}-\mathrm{C}_{3} \mathrm{~N}_{4}$ vs. the applied potential. Experiments were performed in triplicates and results are shown as mean \pm standard deviation. Adapted with permission from reference [51]. Copyright 2017, Nature Publishing Group. (e,f) The distribution of $C_{\geq 2}$ products at different potentials over $\mathrm{N}-\mathrm{GQD} / \mathrm{Cu}-\mathrm{nr}$ during $\mathrm{CO}_{2} \mathrm{RR}$ and CORR experiments. Adapted with permission from reference [59]. Copyright 2020, Wiley-VCH. 
Furthermore, the strategy of CDs hybridization was successfully applied to boost the electrocatalytic $\mathrm{CO}_{2} \mathrm{RR}$ properties of transition metal chalcogenides, usually affected by limited $\mathrm{CO}_{2} \mathrm{RR}$ selectivity and poor electronic conductivity [193]. In particular, a $\mathrm{MoS}_{2} / \mathrm{N}-\mathrm{CDs}$ nanocomposite material with high $\mathrm{N}$-doping content, exhibited a superior activity compared to bare exfoliated $\mathrm{MoS}_{2}$ in $\mathrm{CO}_{2}$-saturated EMIM-BF 4 solutions (94 $\mathrm{mol} \%$ water), showing significantly improved rates, overpotential, and selectivity toward $\mathrm{CO}$ formation ( $\mathrm{FE}=90.2 \%$ at $-0.9 \mathrm{~V}$ vs. RHE) [154]. The origin of the observed boosting effect was ascribed to the presence of N-CDs, which contribute not only to increase the conductivity of the material but also to lower the barrier for rate-limiting ${ }^{*} \mathrm{COOH}$ binding step.

In addition to binary composites based on the combination of CDs and a metal/metaloxide catalyst, Guo et al. recently developed the novel versatile design concept of a three-component hybrid catalyst for electrochemically-driven syngas production from simultaneous $\mathrm{CO}_{2} \mathrm{RR}$ and HER in aqueous electrolyte [51]. As depicted in Figure 7c, the system comprises: (i) an earth-abundant transition metal-based HER catalyst, e.g., $\mathrm{Co}_{3} \mathrm{O}_{4}$; (ii) porous graphitic $\mathrm{C}_{3} \mathrm{~N}_{4}$, accounting for $\mathrm{CO}_{2}$ conversion to $\mathrm{CO}$ due to the presence of $\mathrm{N}$ dopants and ensuring well NPs dispersion; (iii) CDs, acting as the generation site for active hydrogen $\left(\mathrm{H}^{\bullet}\right)$ by trapping $\mathrm{H}^{+}$and $\mathrm{e}^{-}$, thus triggering both the reaction channels. In a $\mathrm{CO}_{2}$-saturated aqueous electrolyte at a close-to-neutral $\mathrm{pH}$, the multi-component catalyst was found to start catalyzing $\mathrm{CO}_{2} \mathrm{RR}$ to $\mathrm{CO}$ at $-0.28 \mathrm{~V}$ vs. RHE, corresponding to a very low overpotential $(0.17 \mathrm{~V})$, and afforded highly stable syngas production over $100 \mathrm{~h}$ electrolysis test [51]. Importantly, the $\mathrm{H}_{2}: \mathrm{CO}$ ratio could be fine-tuned from 0.07:1 to $4: 1$ by controlling the applied potential (Figure $7 \mathrm{~d}$ ) or, alternatively, the amount of $\mathrm{Co}_{3} \mathrm{O}_{4}$ HER catalyst. A series of dedicated experiments unraveled the specific role played by each component within the composite, highlighting the improved $\mathrm{H}^{\bullet}$ stabilization and $\mathrm{CO}_{2} / \mathrm{H}^{+}$adsorption promoted by $\mathrm{CDs}$ as critical steps for $\mathrm{CO}$ production by $\mathrm{C}_{3} \mathrm{~N}_{4}-\mathrm{CDs}$, notwithstanding the $\mathrm{CDs}$ alone could only produce $\mathrm{H}_{2}$. Analogous results were reported for a ternary composite based on a combination of $\mathrm{Au} \mathrm{NPs}$ and CDs loaded on $\mathrm{C}_{3} \mathrm{~N}_{4}$, which was recently found as a highly stable electrocatalyst for $\mathrm{CO}_{2}$ reduction to $\mathrm{CO}$ [50]. Under optimal conditions, the latter achieved a sustained $\mathrm{CO}$ production with a maximum FE of ca. $79.8 \%$ at $-0.5 \mathrm{~V}$ vs. RHE, outperforming the bare Au NPs and the other combinatorial two-component catalysts. The superior $\mathrm{CO}_{2} \mathrm{RR}$ performances of the ternary $\mathrm{Au}-\mathrm{CDs}-\mathrm{C}_{3} \mathrm{~N}_{4}$ composite suggest the presence of a synergistic effect among all the three components. In particular, CDs were supposed to play a major role on the enhanced catalytic response, due to their capability of $\mathrm{CO}_{2} / \mathrm{H}^{+}$adsorption and increased conductivity [50].

In addition to $\mathrm{CO}$ and $\mathrm{HCOO}^{-}$, multi-electron conversion of $\mathrm{CO}_{2}$ into value-added chemicals, such as oxygenates and multi-carbon hydrocarbons $\left(C_{\geq 2}\right)$, is highly desirable. Copper-based electrocatalysts are, so far, the most promising transition metal-based systems for converting $\mathrm{CO}_{2}$ into target $\mathrm{C}_{\geq 2}$ products [194-199]. Although electrochemically-driven $\mathrm{C}-\mathrm{C}$ coupling process efficiently occurs on $\mathrm{Cu}$ catalysts, usually leading to predominant ethylene formation $[200,201], \mathrm{CO}_{2} \mathrm{RR}$ selectivity toward the formation a specific product is generally low. Recently, the presence of CDs in composite $\mathrm{Cu}$ nanocatalysts has been reported to induce a drastic change in selectivity for $\mathrm{CO}_{2} \mathrm{RR}$. For instance, hybrid CuCDs nanocorals were found to catalyze $\mathrm{HCOO}^{-}$formation at low overpotentials $(0.13$ $\mathrm{V}$ ), leading to a maximum $68 \%$ faradaic yield at $-0.7 \mathrm{~V}$ vs. RHE, with a minor amount of detected $\mathrm{CH}_{3} \mathrm{OH}$ accounting for ca. $11 \% \mathrm{FE}$ [52]. In contrast, CDs-free $\mathrm{Cu}$ nanocorals mainly promoted HER under the same conditions, thus indicating the crucial role CDs in catalyzing $\mathrm{CO}_{2} \mathrm{RR}$ over HER. More recently, Chen et al. reported a two-component catalyst based on $\mathrm{CuO}$-derived $\mathrm{Cu}$ nanorods and N-GQDs (N-GQD/Cu-nr), capable of efficiently converting $\mathrm{CO}_{2}$ to multi-carbon alcohols with outstanding high efficiencies [59]. In a flow cell reactor and an alkaline aqueous electrolyte $(1 \mathrm{M} \mathrm{KOH}), \mathrm{NGQ} / \mathrm{Cu}-\mathrm{nr}$ was found to produce $\mathrm{C}_{\geq 2}$ products with $\mathrm{FE}$ up to $80.4 \%$ (corresponding to a $282.1 \mathrm{~mA} \mathrm{~cm}^{-2}$ current density) at $-0.9 \mathrm{~V}$ vs. RHE, of which a $52.4 \% \mathrm{FE}$ accounting for $\mathrm{C}_{\geq 2}$ alcohols (Figure 7e), thus favorably comparing to the state-of-the-art Cu catalysts. More specifically, the presence of N-GQDs, alone capable of catalyzing $\mathrm{CO}_{2} \mathrm{RR}$ to $\mathrm{CO}$ and $\mathrm{C}_{2}$ products, 
significantly contributed to shift selectivity toward the alcohol formation, as indicated by the increase in the alcohol/ethylene ratio from 0.81 on $\mathrm{Cu}-\mathrm{nr}$ to 2.18 on N-GQD/Cu-nr. Notably, the N-GQD/Cu-nr composite catalyst displayed also excellent performances for electrocatalytic $\mathrm{CO}$ reduction reaction (CORR), resulting in an overall $\mathrm{FE}$ for $\mathrm{C}_{\geq 2}$ alcohols formation up to $75.3 \%$ at $-0.7 \mathrm{~V}$ vs. RHE with a partial FE of $27.2 \%$ for n-propanol formation and an over 10-fold higher alcohol-to-ethylene ratio compared to $\mathrm{Cu}$-nr (Figure 7f) [59]. The preferential production of $\mathrm{C}_{\geq 2}$ alcohols on N-GQD/Cu-nr was mainly ascribed to a synergistic cooperation effect between the $\mathrm{Cu}$-based nanorods and N-GQDs, both acting as active sites for $\mathrm{C}_{\geq 2}$ formation. In particular, DFT calculations suggested that the increase oxophilicity due to the incorporation of N-GQDs induced an enhanced stabilization of the oxygenic key ${ }^{*} \mathrm{CH}_{2} \mathrm{CHO}$ intermediate, thus favoring the formation of alcohols through further carbon protonation [59].

\section{Summary and Future Outlook}

In this review, we have surveyed the utilization of carbon dots for photocatalytic and electrocatalytic conversion of $\mathrm{CO}_{2}$ to $\mathrm{C}_{1}$ and $\mathrm{C}_{>2}$ products. Due to their unique optical and electrical properties, the CDs are able to photocatalyze the reduction of $\mathrm{CO}_{2}$ alone or in combination with other components as part of more elaborated catalytic systems. In photocatalytic $\mathrm{CO}_{2} \mathrm{RR}$, the CDs or GQDs act as electron acceptors and strongly contribute to enhance light absorption, while providing active sites for the catalytic reaction. GQDs were also found to be active materials for electrocatalytic $\mathrm{CO}_{2} \mathrm{RR}$, being able to catalyze the process themselves or playing a synergistic role in combination with other components. As metal-free catalysts, GQDs were reported to promote multi-electron $\mathrm{CO}_{2}$ conversion in aqueous electrolytes, leading to the formation of $\mathrm{C}_{1}$ or $\mathrm{C}_{\geq 2}$ hydrocarbons and oxygenates with efficiencies depending on the applied potential. $\mathrm{N}$-doping and the specific configuration of $\mathrm{N}$ sites present in the material are critical for $\mathrm{CO}_{2} \mathrm{RR}$ selectivity and activity of GQDs. The incorporation of pyridinic $\mathrm{N}$ dopants was proposed to provide suitable active sites for catalytic formation of $\mathrm{C}_{\geq 2}$ hydrocarbons and oxygenates via an alternative mechanism to that commonly proposed for $\mathrm{Cu}$-based electrocatalysts. On the other hand, when implemented into binary or ternary metal/metal-oxide composite materials, the GQDs displayed beneficial effects on the catalytic activity of the nanostructured catalysts, improving the overall $\mathrm{CO}_{2} \mathrm{RR}$ performances in terms of selectivity, activity, and overpotential. In hybrid catalysts, the functionalization with GQDs was proposed to alter the adsorption energies of key intermediates, display synergistic effects, favor $\mathrm{CO}_{2}$ uptake and improve conductivity, resulting in optimal $\mathrm{CO}_{2} \mathrm{RR}$ catalytic properties. Furthermore, due to the unique intrinsic physicochemical features of GQDs, metal ion complexation with GQDs was recently proposed as an effective strategy for the synthesis of single-atom catalysts for efficient and selective $\mathrm{CO}_{2} \mathrm{RR}$, preventing metal-metal agglomeration during the pyrolysis step and leading to metal loadings considerably higher than those reported by conventional approaches.

Due to the extreme sensitivity of both photocatalytic and electrocatalytic $\mathrm{CO}_{2} \mathrm{RR}$ performances to the structure and surface composition of carbon dots, future research on the synthesis and characterization of the carbon nanoparticles is required in order to control the composition and its influence on the redox properties. The development of well-defined reproducible protocols for their synthesis and purification is highly desired to improve the rational design of CD-based catalysts. At the same time, the systematic characterization of CD-based materials by using ex situ and operando/in situ spectroscopic techniques is required to establish a direct correlation between structural features and catalytic properties. Operando/in situ spectroscopy also provides a useful experimental tool to get more detailed structural information about the key intermediates involved in the process and the active sites, as well as to real-time monitor their structural evolution under catalytic conditions. This would also improve the rational understanding of the fundamental role played by the CDs in the catalytic reaction, which is an essential step for further improvement of the field. Moreover, the investigation of model systems based on 
the functionalization of molecular catalysts with CDs would also contribute to unravel the influence of CDs on the photochemical, redox, and electronic properties of the catalysts at a fundamental level. We are confident that the overview of the literature data herein presented will contribute to shed light on the role played by the CDs in the electrochemical and photochemical $\mathrm{CO}_{2} \mathrm{RR}$, helping to direct future research in the field.

Author Contributions: B.D.-T., F.F., E.M.-F. and E.P.-G. contributed to bibliography research, discussion of the results and writing of the manuscript. All authors have read and agreed to the published version of the manuscript.

Funding: This research was funded by MINECO (project PID2019-109389RB-I00) and SGR-AGAUR 2017SGR00978. B.D.-T. is thankful to MCIN and ESF for a predoctoral grant (PRE2020-092525). F.F. thanks MCIN/AEI/10.13039/501100011033 for a Juan de la Cierva-Incorporación fellowship (IJC2019-042363-I). E.P.-G. acknowledges financial support from ICIQ, CERCA, and ICREA.

Institutional Review Board Statement: Not applicable.

Informed Consent Statement: Not applicable.

Data Availability Statement: Not applicable.

Conflicts of Interest: The authors declare no conflict of interest.

\section{References}

1. Ritchie, H.; Roser, M. $\mathrm{CO}_{2}$ and Greenhouse Gas Emissions. Our World Data. 2020. Available online: https://ourworldindata.org/ co2-and-other-greenhouse-gas-emissions (accessed on 30 January 2021).

2. Styring, P.; Jansen, D.; de Coninck, H.; Reith, H.; Armstrong, K. Carbon Capture and Utilisation in the Green Economy; Center for Low Carbon Futures: New York, NY, USA, 2011; ISBN 9780957258815.

3. Fontecilla-Camps, J.C.; Amara, P.; Cavazza, C.; Nicolet, Y.; Volbeda, A. Structure-function relationships of anaerobic gasprocessing metalloenzymes. Nature 2009, 460, 814-822. [CrossRef] [PubMed]

4. Liu, Q.; Wu, L.; Jackstell, R.; Beller, M. Using carbon dioxide as a building block in organic synthesis. Nat. Commun. 2015, 6, 1-15. [CrossRef]

5. Franco, F.; Rettenmaier, C.; Jeon, H.S.; Roldan Cuenya, B. Transition metal-based catalysts for the electrochemical $\mathrm{CO}_{2}$ reduction: From atoms and molecules to nanostructured materials. Chem. Soc. Rev. 2020, 49, 6884-6946. [CrossRef] [PubMed]

6. Kinzel, N.W.; Werlé, C.; Leitner, W. Transition Metal Complexes as Catalysts for the Electroconversion of $\mathrm{CO}_{2}$ : An Organometallic Perspective. Angew. Chemie Int. Ed. 2021, 60, 11628-11686. [CrossRef] [PubMed]

7. Li, D.; Kassymova, M.; Cai, X.; Zang, S.-Q.; Jiang, H.-L. Photocatalytic $\mathrm{CO}_{2}$ reduction over metal-organic framework-based materials. Coord. Chem. Rev. 2020, 412, 213262. [CrossRef]

8. Perazio, A.; Lowe, G.; Gobetto, R.; Bonin, J.; Robert, M. Light-driven catalytic conversion of $\mathrm{CO}_{2}$ with heterogenized molecular catalysts based on fourth period transition metals. Coord. Chem. Rev. 2021, 443, 214018. [CrossRef]

9. Boutin, E.; Merakeb, L.; Ma, B.; Boudy, B.; Wang, M.; Bonin, J.; Anxolabéhère-Mallart, E.; Robert, M. Molecular catalysis of CO 2 reduction: Recent advances and perspectives in electrochemical and light-driven processes with selected $\mathrm{Fe}, \mathrm{Ni}$ and $\mathrm{Co}$ aza macrocyclic and polypyridine complexes. Chem. Soc. Rev. 2020, 49, 5772-5809. [CrossRef] [PubMed]

10. Liu, X.; Dai, L. Carbon-based metal-free catalysts. Nat. Rev. Mater. 2016, 1, 1-12. [CrossRef]

11. Yang, N.; Waldvogel, S.R.; Jiang, X. Electrochemistry of carbon dioxide on carbon electrodes. ACS Appl. Mater. Interfaces 2016, 8 , 28357-28371. [CrossRef]

12. Dai, L. Carbon-based catalysts for metal-free electrocatalysis. Curr. Opin. Electrochem. 2017, 4, 18-25. [CrossRef]

13. Wu, J.; Sharifi, T.; Gao, Y.; Zhang, T.; Ajayan, P.M. Emerging Carbon-Based Heterogeneous Catalysts for Electrochemical Reduction of Carbon Dioxide into Value-Added Chemicals. Adv. Mater. 2019, 31, 1804257. [CrossRef] [PubMed]

14. Jia, C.; Dastafkan, K.; Ren, W.; Yang, W.; Zhao, C. Carbon-based catalysts for electrochemical $\mathrm{CO}_{2}$ reduction. Sustain. Energy Fuels 2019, 3, 2890-2906. [CrossRef]

15. Messias, S.; Nunes da Ponte, M.; S Reis-Machado, A. Carbon Materials as Cathode Constituents for Electrochemical $\mathrm{CO}_{2}$ Reduction-A Review. C 2019, 5, 83. [CrossRef]

16. Gawande, M.B.; Fornasiero, P.; Zbořil, R. Carbon-based single-atom catalysts for advanced applications. ACS Catal. 2020, 10, 2231-2259. [CrossRef]

17. Wu, J.; Ma, S.; Sun, J.; Gold, J.I.; Tiwary, C.; Kim, B.; Zhu, L.; Chopra, N.; Odeh, I.N.; Vajtai, R.; et al. A metal-free electrocatalyst for carbon dioxide reduction to multi-carbon hydrocarbons and oxygenates. Nat. Commun. 2016, 7, 1-6. [CrossRef] [PubMed]

18. Zhao, K.; Quan, X. Carbon-based materials for electrochemical reduction of $\mathrm{CO}_{2}$ to $\mathrm{C} 2+$ oxygenates: Recent progress and remaining challenges. ACS Catal. 2021, 11, 2076-2097. [CrossRef]

19. Yeh, T.; Teng, C.; Chen, S.; Teng, H. Nitrogen-doped graphene oxide quantum dots as photocatalysts for overall water-splitting under visible light Illumination. Adv. Mater. 2014, 26, 3297-3303. [CrossRef] 
20. Li, Y.; Zhao, Y.; Cheng, H.; Hu, Y.; Shi, G.; Dai, L.; Qu, L. Nitrogen-doped graphene quantum dots with oxygen-rich functional groups. J. Am. Chem. Soc. 2012, 134, 15-18. [CrossRef]

21. Jana, J.; Ngo, Y.-L.T.; Chung, J.S.; Hur, S.H. Contribution of Carbon Dot Nanoparticles in Electrocatalysis: Development in Energy Conversion Process. J. Electrochem. Sci. Technol. 2020, 11, 220-237. [CrossRef]

22. Zhang, Z.; Yi, G.; Li, P.; Zhang, X.; Fan, H.; Zhang, Y.; Wang, X.; Zhang, C. A minireview on doped carbon dots for photocatalytic and electrocatalytic applications. Nanoscale 2020, 12, 13899-13906. [CrossRef]

23. Hu, C.; Li, M.; Qiu, J.; Sun, Y.-P. Design and fabrication of carbon dots for energy conversion and storage. Chem. Soc. Rev. 2019, 48, 2315-2337. [CrossRef] [PubMed]

24. Cao, L.; Shiral Fernando, K.A.; Liang, W.; Seilkop, A.; Monica Veca, L.; Sun, Y.-P.; Bunker, C.E. Carbon dots for energy conversion applications. J. Appl. Phys. 2019, 125, 220903. [CrossRef]

25. Shaari, N.; Kamarudin, S.K.; Bahru, R. Carbon and graphene quantum dots in fuel cell application: An overview. Int. J. Energy Res. 2021, 45, 1396-1424. [CrossRef]

26. He, C.; Xu, P.; Zhang, X.; Long, W. The synthetic strategies, photoluminescence mechanisms and promising applications of carbon dots: Current state and future perspective. Carbon N. Y. 2022, 186, 91-127. [CrossRef]

27. Yan, X.; Cui, X.; Li, B.; Li, L. Large, solution-processable graphene quantum dots as light absorbers for photovoltaics. Nano Lett. 2010, 10, 1869-1873. [CrossRef]

28. Yang, S.-T.; Cao, L.; Luo, P.G.; Lu, F.; Wang, X.; Wang, H.; Meziani, M.J.; Liu, Y.; Qi, G.; Sun, Y.-P. Carbon dots for optical imaging in vivo. J. Am. Chem. Soc. 2009, 131, 11308-11309. [CrossRef]

29. Xu, X.; Ray, R.; Gu, Y.; Ploehn, H.J.; Gearheart, L.; Raker, K.; Scrivens, W.A. Electrophoretic analysis and purification of fluorescent single-walled carbon nanotube fragments. J. Am. Chem. Soc. 2004, 126, 12736-12737. [CrossRef]

30. Sun, Y.-P.; Zhou, B.; Lin, Y.; Wang, W.; Fernando, K.A.S.; Pathak, P.; Meziani, M.J.; Harruff, B.A.; Wang, X.; Wang, H.; et al. Quantum-sized carbon dots for bright and colorful photoluminescence. J. Am. Chem. Soc. 2006, 128, 7756-7757. [CrossRef]

31. Gao, J.; Zhu, M.; Huang, H.; Liu, Y.; Kang, Z. Advances, challenges and promises of carbon dots. Inorg. Chem. Front. 2017, 4, 1963-1986. [CrossRef]

32. Ge, L.; Pan, N.; Jin, J.; Wang, P.; LeCroy, G.E.; Liang, W.; Yang, L.; Teisl, L.R.; Tang, Y.; Sun, Y.-P. Systematic comparison of carbon dots from different preparations - consistent optical properties and photoinduced redox characteristics in visible spectrum and structural and mechanistic implications. J. Phys. Chem. C 2018, 122, 21667-21676. [CrossRef]

33. Qin, X.; Zhu, S.; Xiao, F.; Zhang, L.; Shao, M. Active sites on heterogeneous single-iron-atom electrocatalysts in $\mathrm{CO}_{2}$ reduction reaction. ACS Energy Lett. 2019, 4, 1778-1783. [CrossRef]

34. Hu, X.-M.; Hval, H.H.; Bjerglund, E.T.; Dalgaard, K.J.; Madsen, M.R.; Pohl, M.-M.; Welter, E.; Lamagni, P.; Buhl, K.B.; Bremholm, M. Selective $\mathrm{CO}_{2}$ reduction to $\mathrm{CO}$ in water using earth-abundant metal and nitrogen-doped carbon electrocatalysts. ACS Catal. 2018, 8, 6255-6264. [CrossRef]

35. Pillar-Little, T.J.; Wanninayake, N.; Nease, L.; Heidary, D.K.; Glazer, E.C.; Kim, D.Y. Superior photodynamic effect of carbon quantum dots through both type I and type II pathways: Detailed comparison study of top-down-synthesized and bottom-upsynthesized carbon quantum dots. Carbon N. Y. 2018, 140, 616-623. [CrossRef]

36. Chichkov, B.N.; Momma, C.; Nolte, S.; Von Alvensleben, F.; Tünnermann, A. Femtosecond, picosecond and nanosecond laser ablation of solids. Appl. Phys. A 1996, 63, 109-115. [CrossRef]

37. Kaczmarek, A.; Hoffman, J.; Morgiel, J.; Mościcki, T.; Stobiński, L.; Szymański, Z.; Małolepszy, A. Luminescent Carbon Dots Synthesized by the Laser Ablation of Graphite in Polyethylenimine and Ethylenediamine. Materials (Basel) 2021, 14, 729. [CrossRef]

38. Orooji, Y.; Ghanbari Gol, H.; Jaleh, B.; Rashidian Vaziri, M.R.; Eslamipanah, M. Large Optical Nonlinearity of the Activated Carbon Nanoparticles Prepared by Laser Ablation. Nanomaterials 2021, 11, 737. [CrossRef] [PubMed]

39. Reyes, D.; Camacho, M.; Camacho, M.; Mayorga, M.; Weathers, D.; Salamo, G.; Wang, Z.; Neogi, A. Laser ablated carbon nanodots for light emission. Nanoscale Res. Lett. 2016, 11, 1-11. [CrossRef] [PubMed]

40. Kushwaha, N.; Mittal, J.; Pandey, S.; Kumar, R. High temperature acidic oxidation of multiwalled Carbon nanotubes and synthesis of Graphene quantum dots. Int. J. Nano Dimens. 2018, 9, 191-197.

41. Iannazzo, D.; Pistone, A.; Salamò, M.; Galvagno, S.; Romeo, R.; Giofré, S.V.; Branca, C.; Visalli, G.; Di Pietro, A. Graphene quantum dots for cancer targeted drug delivery. Int. J. Pharm. 2017, 518, 185-192. [CrossRef] [PubMed]

42. Saheeda, P.; Sabira, K.; Dhaneesha, M.; Jayaleksmi, S. Investigation on the $\mathrm{pH}$-independent photoluminescence emission from carbon dots impregnated on polymer matrix. Luminescence 2018, 33, 22-28. [CrossRef]

43. Hu, C.; Yu, C.; Li, M.; Wang, X.; Yang, J.; Zhao, Z.; Eychmüller, A.; Sun, Y.; Qiu, J. Chemically tailoring coal to fluorescent carbon dots with tuned size and their capacity for $\mathrm{Cu}$ (II) detection. Small 2014, 10, 4926-4933. [CrossRef]

44. Yan, Y.; Chen, J.; Li, N.; Tian, J.; Li, K.; Jiang, J.; Liu, J.; Tian, Q.; Chen, P. Systematic Bandgap Engineering of Graphene Quantum Dots and Applications for Photocatalytic Water Splitting and $\mathrm{CO}_{2}$ Reduction. ACS Nano 2018, 12, 3523-3532. [CrossRef] [PubMed]

45. Wang, Z.; Xia, J.; Zhou, C.; Via, B.; Xia, Y.; Zhang, F.; Li, Y.; Xia, L.; Tang, J. Synthesis of strongly green-photoluminescent graphene quantum dots for drug carrier. Colloids Surf. B Biointerfaces 2013, 112, 192-196. [CrossRef]

46. Liu, Z.; Wang, Z.; Qing, S.; Xue, N.; Jia, S.; Zhang, L.; Li, L.; Li, N.; Shi, L.; Chen, J. Improving methane selectivity of photo-induced $\mathrm{CO}_{2}$ reduction on carbon dots through modification of nitrogen-containing groups and graphitization. Appl. Catal. B Environ. 2018, 232, 86-92. [CrossRef] 
47. Jin, S.; Ni, Y.; Hao, Z.; Zhang, K.; Lu, Y.; Yan, Z.; Wei, Y.; Lu, Y.; Chan, T.; Chen, J. A Universal Graphene Quantum Dot Tethering Design Strategy to Synthesize Single-Atom Catalysts. Angew. Chemie Int. Ed. 2020, 59, 21885-21889. [CrossRef] [PubMed]

48. Zhou, J.; Booker, C.; Li, R.; Zhou, X.; Sham, T.-K.; Sun, X.; Ding, Z. An electrochemical avenue to blue luminescent nanocrystals from multiwalled carbon nanotubes (MWCNTs). J. Am. Chem. Soc. 2007, 129, 744-745. [CrossRef] [PubMed]

49. Li, H.; He, X.; Kang, Z.; Huang, H.; Liu, Y.; Liu, J.; Lian, S.; Tsang, C.H.A.; Yang, X.; Lee, S.-T. Water-Soluble Fluorescent Carbon Quantum Dots and Photocatalyst Design. Angew. Chemie 2010, 122, 4532-4536. [CrossRef]

50. Zhao, S.; Tang, Z.; Guo, S.; Han, M.; Zhu, C.; Zhou, Y.; Bai, L.; Gao, J.; Huang, H.; Li, Y.; et al. Enhanced Activity for CO 2 Electroreduction on a Highly Active and Stable Ternary Au-CDots-C3N4 Electrocatalyst. ACS Catal. 2018, 8, 188-197. [CrossRef]

51. Guo, S.; Zhao, S.; Wu, X.; Li, H.; Zhou, Y.; Zhu, C.; Yang, N.; Jiang, X.; Gao, J.; Bai, L.; et al. A $\mathrm{Co}_{3} \mathrm{O}_{4}-\mathrm{CDots}_{-} \mathrm{C}_{3} \mathrm{~N}_{4}$ three component electrocatalyst design concept for efficient and tunable $\mathrm{CO}_{2}$ reduction to syngas. Nat. Commun. 2017, 8, 1-9. [CrossRef]

52. Guo, S.; Zhao, S.; Gao, J.; Zhu, C.; Wu, X.; Fu, Y.; Huang, H.; Liu, Y.; Kang, Z. Cu-CDots nanocorals as electrocatalyst for highly efficient $\mathrm{CO}_{2}$ reduction to formate. Nanoscale 2017, 9, 298-304. [CrossRef]

53. Li, Y.; Hu, Y.; Zhao, Y.; Shi, G.; Deng, L.; Hou, Y.; Qu, L. An electrochemical avenue to green-luminescent graphene quantum dots as potential electron-acceptors for photovoltaics. Adv. Mater. 2011, 23, 776-780. [CrossRef] [PubMed]

54. Zhou, Q.; Yuan, G.; Lin, M.; Wang, P.; Li, S.; Tang, J.; Lin, J.; Huang, Y.; Zhang, Y. Large-scale electrochemical fabrication of nitrogen-doped carbon quantum dots and their application as corrosion inhibitor for copper. J. Mater. Sci. 2021, 56, 12909-12919. [CrossRef]

55. Zheng, X.; Ren, S.; Wang, L.; Gai, Q.; Dong, Q.; Liu, W. Controllable functionalization of carbon dots as fluorescent sensors for independent $\mathrm{Cr}$ (VI), Fe (III) and Cu (II) ions detection. J. Photochem. Photobiol. A Chem. 2021, 417, 113359. [CrossRef]

56. Li, L.; Ji, J.; Fei, R.; Wang, C.; Lu, Q.; Zhang, J.; Jiang, L.; Zhu, J. A facile microwave avenue to electrochemiluminescent two-color graphene quantum dots. Adv. Funct. Mater. 2012, 22, 2971-2979. [CrossRef]

57. Zhuo, S.; Shao, M.; Lee, S.-T. Upconversion and downconversion fluorescent graphene quantum dots: Ultrasonic preparation and photocatalysis. ACS Nano 2012, 6, 1059-1064. [CrossRef]

58. Prasad, K.P.; Chen, Y.; Sk, M.A.; Than, A.; Wang, Y.; Sun, H.; Lim, K.-H.; Dong, X.; Chen, P. Fluorescent quantum dots derived from PEDOT and their applications in optical imaging and sensing. Mater. Horizons 2014, 1, 529-534. [CrossRef]

59. Chen, C.; Yan, X.; Liu, S.; Wu, Y.; Wan, Q.; Sun, X.; Zhu, Q.; Liu, H.; Ma, J.; Zheng, L.; et al. Highly Efficient Electroreduction of $\mathrm{CO}_{2}$ to $\mathrm{C} 2+$ Alcohols on Heterogeneous Dual Active Sites. Angew. Chemie Int. Ed. 2020, 59, 16459-16464. [CrossRef]

60. Pizzetti, M.; Petricci, E.; Tecnologico, C. Heterogeneous catalysis under microwave heating. La Chim. l'Industria 2012, 78-81.

61. Baluta, S.; Lesiak, A.; Cabaj, J. Simple and cost-effective electrochemical method for norepinephrine determination based on carbon dots and tyrosinase. Sensors (Switzerland) 2020, 20, 1-13. [CrossRef]

62. Lin, P.-Y.; Hsieh, C.-W.; Kung, M.-L.; Chu, L.-Y.; Huang, H.-J.; Chen, H.-T.; Wu, D.-C.; Kuo, C.-H.; Hsieh, S.-L.; Hsieh, S Eco-friendly synthesis of shrimp egg-derived carbon dots for fluorescent bioimaging. J. Biotechnol. 2014, 189, 114-119. [CrossRef]

63. Li, W.; Liu, Y.; Wu, M.; Feng, X.; Redfern, S.A.T.; Shang, Y.; Yong, X.; Feng, T.; Wu, K.; Liu, Z.; et al. Carbon-Quantum-DotsLoaded Ruthenium Nanoparticles as an Efficient Electrocatalyst for Hydrogen Production in Alkaline Media. Adv. Mater. 2018, 30, 1800676. [CrossRef] [PubMed]

64. Qing, W.; Chen, K.; Yang, Y.; Wang, Y.; Liu, X. Cu2+-doped carbon dots as fluorescence probe for specific recognition of Cr(VI) and its antimicrobial activity. Microchem. J. 2020, 152, 104262. [CrossRef]

65. Hong, W.T.; Yang, H.K. Luminescent properties of carbon dots originated from pine pollen foranti-counterfeiting application. Opt. LASER Technol. 2022, 145, 107452. [CrossRef]

66. Kim, D.; Jo, G.; Chae, Y.; Subramani, S.; Lee, B.Y.; Kim, E.J.; Ji, M.-K.; Sim, U.; Hyun, H. Bioinspired Camellia japonica carbon dots with high near-infrared absorbance for efficient photothermal cancer therapy. Nanoscale 2021, 13, 14426-14434. [CrossRef]

67. Shaik, S.A.; Sengupta, S.; Varma, R.S.; Gawande, M.B.; Goswami, A. Syntheses of N-Doped Carbon Quantum Dots (NCQDs) from Bioderived Precursors: A Timely Update. ACS Sustain. Chem. Eng. 2021, 9, 3-49. [CrossRef]

68. Sendão, R.; de Yuso, M.D.V.M.; Algarra, M.; Esteves da Silva, J.C.G.; Pinto da Silva, L. Comparative life cycle assessment of bottom-up synthesis routes for carbon dots derived from citric acid and urea. J. Clean. Prod. 2020, 254, 1-10. [CrossRef]

69. Ren, J.; Malfatti, L.; Innocenzi, P. Citric Acid Derived Carbon Dots, the Challenge of Understanding the Synthesis-Structure Relationship. C 2020, 7, 2. [CrossRef]

70. Song, Y.; Zhu, S.; Zhang, S.; Fu, Y.; Wang, L.; Zhao, X.; Yang, B. Investigation from chemical structure to photoluminescent mechanism: A type of carbon dots from the pyrolysis of citric acid and an amine. J. Mater. Chem. C 2015, 3, 5976-5984. [CrossRef]

71. Duan, P.; Zhi, B.; Coburn, L.; Haynes, C.L.; Schmidt-Rohr, K. A molecular fluorophore in citric acid/ethylenediamine carbon dots identified and quantified by multinuclear solid-state nuclear magnetic resonance. Magn. Reson. Chem. 2020, 58, 1130-1138. [CrossRef]

72. Li, M.; Wang, M.; Zhu, L.; Li, Y.; Yan, Z.; Shen, Z.; Cao, X. Facile microwave assisted synthesis of N-rich carbon quantum dots/dual-phase $\mathrm{TiO}_{2}$ heterostructured nanocomposites with high activity in $\mathrm{CO}_{2}$ photoreduction. Appl. Catal. B Environ. 2018, 231, 269-276. [CrossRef]

73. Christé, S.; da Silva, J.C.G.E.; da Silva, L.P. Evaluation of the environmental impact and efficiency of N-doping strategies in the synthesis of carbon dots. Materials 2020, 13, 504. [CrossRef] [PubMed]

74. Hinterberger, V.; Damm, C.; Haines, P.; Guldi, D.M.; Peukert, W. Purification and structural elucidation of carbon dots by column chromatography. Nanoscale 2019, 11, 8464-8474. [CrossRef] [PubMed] 
75. LeCroy, G.E.; Yang, S.T.; Yang, F.; Liu, Y.; Fernando, K.A.S.; Bunker, C.E.; Hu, Y.; Luo, P.G.; Sun, Y.P. Functionalized carbon nanoparticles: Syntheses and applications in optical bioimaging and energy conversion. Coord. Chem. Rev. 2016, 320-321, 66-81. [CrossRef]

76. Li, L.; Li, Y.; Ye, Y.; Guo, R.; Wang, A.; Zou, G.; Hou, H.; Ji, X. Kilogram-Scale Synthesis and Functionalization of Carbon Dots for Superior Electrochemical Potassium Storage. ACS Nano 2021, 15, 6872-6885. [CrossRef]

77. Dong, W.; Zhou, S.; Dong, Y.; Wang, J.; Ge, X.; Sui, L. The preparation of ethylenediamine-modified fluorescent carbon dots and their use in imaging of cells. Luminescence 2015, 30, 867-871. [CrossRef]

78. Zhong, H.; Sa, R.; Lv, H.; Yang, S.; Yuan, D.; Wang, X.; Wang, R. Covalent Organic Framework Hosting Metalloporphyrin-Based Carbon Dots for Visible-Light-Driven Selective $\mathrm{CO}_{2}$ Reduction. Adv. Funct. Mater. 2020, 30, 2-9. [CrossRef]

79. Hao, A.; Guo, X.; Wu, Q.; Sun, Y.; Cong, C.; Liu, W. Exploring the interactions between polyethyleneimine modified fluorescent carbon dots and bovine serum albumin by spectroscopic methods. J. Lumin. 2016, 170, 90-96. [CrossRef]

80. Cailotto, S.; Amadio, E.; Facchin, M.; Selva, M.; Pontoglio, E.; Rizzolio, F.; Riello, P.; Toffoli, G.; Benedetti, A.; Perosa, A. Carbon dots from sugars and ascorbic acid: Role of the precursors on morphology, properties, toxicity, and drug uptake. ACS Med. Chem. Lett. 2018, 9, 832-837. [CrossRef]

81. Yang, L.; Jiang, W.; Qiu, L.; Jiang, X.; Zuo, D.; Wang, D.; Yang, L. One pot synthesis of highly luminescent polyethylene glycol anchored carbon dots functionalized with a nuclear localization signal peptide for cell nucleus imaging. Nanoscale 2015, 7, 6104-6113. [CrossRef]

82. Peng, Z.; Ji, C.; Zhou, Y.; Zhao, T.; Leblanc, R.M. Polyethylene glycol (PEG) derived carbon dots: Preparation and applications. Appl. Mater. Today 2020, 20, 100677. [CrossRef]

83. Wei, X.; Wang, C.; Ding, S.; Yang, K.; Tian, F.; Li, F. One-step synthesis of Ag nanoparticles/carbon dots/TiO $\mathrm{T}_{2}$ nanotube arrays composite photocatalyst with enhanced photocatalytic activity. J. Environ. Chem. Eng. 2021, 9, 104729. [CrossRef]

84. Strauss, V.; Wang, H.; Delacroix, S.; Ledendecker, M.; Wessig, P. Carbon nanodots revised: The thermal citric acid/urea reaction. Chem. Sci. 2020, 11, 8256-8266. [CrossRef] [PubMed]

85. Kasprzyk, W.; Świergosz, T.; Bednarz, S.; Walas, K.; Bashmakova, N.V.; Bogdał, D. Luminescence phenomena of carbon dots derived from citric acid and urea-a molecular insight. Nanoscale 2018, 10, 13889-13894. [CrossRef] [PubMed]

86. Sendão, R.M.S.; Crista, D.M.A.; Afonso, A.C.P.; Martínez De Yuso, M.D.V.; Algarra, M.; Esteves Da Silva, J.C.G.; Pinto Da Silva, L. Insight into the hybrid luminescence showed by carbon dots and molecular fluorophores in solution. Phys. Chem. Chem. Phys. 2019, 21, 20919-20926. [CrossRef] [PubMed]

87. Miao, X.; Qu, D.; Yang, D.; Nie, B.; Zhao, Y.; Fan, H.; Sun, Z. Synthesis of Carbon Dots with Multiple Color Emission by Controlled Graphitization and Surface Functionalization. Adv. Mater. 2018, 30, 1-8. [CrossRef] [PubMed]

88. Jo, W.K.; Kumar, S.; Tonda, S. N-doped C dot/CoAl-layered double hydroxide/g- $\mathrm{C}_{3} \mathrm{~N}_{4}$ hybrid composites for efficient and selective solar-driven conversion of $\mathrm{CO}_{2}$ into $\mathrm{CH}_{4}$. Compos. Part B Eng. 2019, 176, 107212. [CrossRef]

89. Wang, Y.; Liu, X.; Han, X.; Godin, R.; Chen, J.; Zhou, W.; Jiang, C.; Thompson, J.F.; Mustafa, K.B.; Shevlin, S.A.; et al. Unique hole-accepting carbon-dots promoting selective carbon dioxide reduction nearly $100 \%$ to methanol by pure water. Nat. Commun. 2020, 11, 1-9. [CrossRef]

90. Yadav, R.M.; Li, Z.; Zhang, T.; Sahin, O.; Roy, S.; Gao, G.; Guo, H.; Vajtai, R.; Wang, L.; Ajayan, P.M. Amine Functionalized Carbon Nanodots Electrocatalysts Converting Carbon Dioxide to Methane. Adv. Mater. 2021, 2105690. [CrossRef]

91. Chowdhury, D.; Gogoi, N.; Majumdar, G. Fluorescent carbon dots obtained from chitosan gel. RSC Adv. 2012, 2, 12156-12159. [CrossRef]

92. Sonsin, A.F.; Nascimento, S.M.S.; Albuquerque, I.M.B.; Silva, E.C.O.; Rocha, J.C.A.; Oliveira, R.S.; Barbosa, C.D.E.S.; Souza, S.T.; Fonseca, E.J.S. Temperature-dependence on the optical properties of chitosan carbon dots in the solid state. RSC Adv. 2021, 11, 2767-2773. [CrossRef]

93. Sun, L.; Zhang, H.; Wang, Y.; Xiong, Z.; Zhao, X.; Xia, Y. Chitosan-derived N-doped carbon dots for fluorescent determination of nitrite and bacteria imaging. Spectrochim. Acta Part A Mol. Biomol. Spectrosc. 2021, 251, 119468. [CrossRef] [PubMed]

94. Konwar, A.; Gogoi, N.; Majumdar, G.; Chowdhury, D. Green chitosan-carbon dots nanocomposite hydrogel film with superior properties. Carbohydr. Polym. 2015, 115, 238-245. [CrossRef] [PubMed]

95. Rong, M.; Liang, Y.; Zhao, D.; Chen, B.; Pan, C.; Deng, X.; Chen, Y.; He, J. A ratiometric fluorescence visual test paper for an anthrax biomarker based on functionalized manganese-doped carbon dots. Sensors Actuators, B Chem. 2018, 265, 498-505. [CrossRef]

96. Pajewska-Szmyt, M.; Buszewski, B.; Gadzała-Kopciuch, R. Sulphur and nitrogen doped carbon dots synthesis by microwave assisted method as quantitative analytical nano-tool for mercury ion sensing. Mater. Chem. Phys. 2020, 242, 122484. [CrossRef]

97. Fu, J.; Wang, Y.; Liu, J.; Huang, K.; Chen, Y.; Li, Y.; Zhu, J.J. Low Overpotential for Electrochemically Reducing $\mathrm{CO}_{2}$ to $\mathrm{CO}$ on Nitrogen-Doped Graphene Quantum Dots-Wrapped Single-Crystalline Gold Nanoparticles. ACS Energy Lett. 2018, 3, $946-951$. [CrossRef]

98. Jiang, K.; Sun, S.; Zhang, L.; Lu, Y.; Wu, A.; Cai, C.; Lin, H. Red, Green, and Blue Luminescence by Carbon Dots: Full-Color Emission Tuning and Multicolor Cellular Imaging. Angew. Chemie 2015, 127, 5450-5453. [CrossRef]

99. Chen, Z.; Mou, K.; Wang, X.; Liu, L. Nitrogen-Doped Graphene Quantum Dots Enhance the Activity of Bi 2 O 3 Nanosheets for Electrochemical Reduction of $\mathrm{CO}_{2}$ in a Wide Negative Potential Region. Angew. Chemie 2018, 130, 12972-12976. [CrossRef] 
100. Zhang, T.; Li, W.; Huang, K.; Guo, H.; Li, Z.; Fang, Y.; Yadav, R.M.; Shanov, V.; Ajayan, P.M.; Wang, L. Regulation of functional groups on graphene quantum dots directs selective $\mathrm{CO}_{2}$ to $\mathrm{CH} 4$ conversion. Nat. Commun. 2021, 12, 1-9. [CrossRef]

101. Xia, C.; Qiu, Y.; Xia, Y.; Zhu, P.; King, G.; Zhang, X.; Wu, Z.; Kim, J.Y.T.; Cullen, D.A.; Zheng, D. General synthesis of single-atom catalysts with high metal loading using graphene quantum dots. Nat. Chem. 2021, 13, 887-894. [CrossRef]

102. Suslick, K.S. Sonokemija. Znan. Američko udruženje za Napred. Znan. 1991, 247, 1439-1445.

103. Ong, W.J.; Putri, L.K.; Tan, Y.C.; Tan, L.L.; Li, N.; Ng, Y.H.; Wen, X.; Chai, S.P. Unravelling charge carrier dynamics in protonated gC3N4 interfaced with carbon nanodots as co-catalysts toward enhanced photocatalytic $\mathrm{CO}_{2}$ reduction: A combined experimental and first-principles DFT study. Nano Res. 2017, 10, 1673-1696. [CrossRef]

104. Li, H.; Deng, Y.; Liu, Y.; Zeng, X.; Wiley, D.; Huang, J. Carbon quantum dots and carbon layer double protected cuprous oxide for efficient visible light $\mathrm{CO}_{2}$ reduction. Chem. Commun. 2019, 55, 4419-4422. [CrossRef] [PubMed]

105. Li, H.; Zhang, X.; MacFarlane, D.R. Carbon quantum dots $/ \mathrm{Cu} 2 \mathrm{O}$ heterostructures for solar-light-driven conversion of $\mathrm{CO}_{2}$ to methanol. Adv. Energy Mater. 2015, 5, 1401077. [CrossRef]

106. Gao, J.; Zhao, S.; Guo, S.; Wang, H.; Sun, Y.; Yao, B.; Liu, Y.; Huang, H.; Kang, Z. Carbon quantum dot-covered porous Ag with enhanced activity for selective electroreduction of $\mathrm{CO}_{2}$ to $\mathrm{CO}$. Inorg. Chem. Front. 2019, 6, 1453-1460. [CrossRef]

107. Cao, L.; Sahu, S.; Anilkumar, P.; Bunker, C.E.; Xu, J.; Fernando, K.A.S.; Wang, P.; Guliants, E.A.; Tackett, K.N.; Sun, Y.P. Carbon nanoparticles as visible-light photocatalysts for efficient $\mathrm{CO}_{2}$ conversion and beyond. J. Am. Chem. Soc. 2011, 133, $4754-4757$. [CrossRef]

108. Zhou, Y.; Mintz, K.J.; Oztan, C.Y.; Hettiarachchi, S.D.; Peng, Z.; Seven, E.S.; Liyanage, P.Y.; De La Torre, S.; Celik, E.; Leblanc, R.M. Embedding carbon dots in superabsorbent polymers for additive manufacturing. Polymers 2018, 10, 921. [CrossRef]

109. Dehvari, K.; Liu, K.Y.; Tseng, P.-J.; Gedda, G.; Girma, W.M.; Chang, J.-Y. Sonochemical-assisted green synthesis of nitrogen-doped carbon dots from crab shell as targeted nanoprobes for cell imaging. J. Taiwan Inst. Chem. Eng. 2019, 95, 495-503. [CrossRef]

110. Xu, Z.Q.; Yang, L.Y.; Fan, X.Y.; Jin, J.C.; Mei, J.; Peng, W.; Jiang, F.L.; Xiao, Q.; Liu, Y. Low temperature synthesis of highly stable phosphate functionalized two color carbon nanodots and their application in cell imaging. Carbon N. Y. 2014, 66, 351-360. [CrossRef]

111. Liu, Y.; Liu, C.; Zhang, Z. Graphitized carbon dots emitting strong green photoluminescence. J. Mater. Chem. C 2013, 1, $4902-4907$. [CrossRef]

112. Gong, X.; Lu, W.; Liu, Y.; Li, Z.; Shuang, S.; Dong, C.; Choi, M.M.F. Low temperature synthesis of phosphorous and nitrogen co-doped yellow fluorescent carbon dots for sensing and bioimaging. J. Mater. Chem. B 2015, 3, 6813-6819. [CrossRef]

113. Qin, X.; Liu, J.; Zhang, Q.; Chen, W.; Zhong, X.; He, J. Synthesis of Yellow-Fluorescent Carbon Nano-dots by Microplasma for Imaging and Photocatalytic Inactivation of Cancer Cells. Nanoscale Res. Lett. 2021, 16, 1-9. [CrossRef] [PubMed]

114. Zhang, Z.; Shi, Y.; Pan, Y.; Cheng, X.; Zhang, L.; Chen, J.; Li, M.J.; Yi, C. Quinoline derivative-functionalized carbon dots as a fluorescent nanosensor for sensing and intracellular imaging of Zn2+. J. Mater. Chem. B 2014, 2, 5020-5027. [CrossRef] [PubMed]

115. Wang, F.; Pang, S.; Wang, L.; Li, Q.; Kreiter, M.; Liu, C.Y. One-step synthesis of highly luminescent carbon dots in noncoordinating solvents. Chem. Mater. 2010, 22, 4528-4530. [CrossRef]

116. Guo, C.X.; Zhao, D.; Zhao, Q.; Wang, P.; Lu, X. Na+-functionalized carbon quantum dots: A new draw solute in forward osmosis for seawater desalination. Chem. Commun. 2014, 50, 7318-7321. [CrossRef] [PubMed]

117. Das, A.; Arefina, I.A.; Danilov, D.V.; Koroleva, A.V.; Zhizhin, E.V.; Parfenov, P.S.; Kuznetsova, V.A.; Ismagilov, A.O.; Litvin, A.P.; Fedorov, A. V Chiral carbon dots based on L/D-cysteine produced via room temperature surface modification and one-pot carbonization. Nanoscale 2021, 13, 8058-8066. [CrossRef]

118. Yuan, Y.H.; Liu, Z.X.; Li, R.S.; Zou, H.Y.; Lin, M.; Liu, H.; Huang, C.Z. Synthesis of nitrogen-doping carbon dots with different photoluminescence properties by controlling the surface states. Nanoscale 2016, 8, 6770-6776. [CrossRef]

119. Khavlyuk, P.D.; Stepanidenko, E.A.; Bondarenko, D.P.; Danilov, D.V.; Koroleva, A.V.; Baranov, A.V.; Maslov, V.G.; Kasak, P.; Fedorov, A.V.; Ushakova, E.V. The influence of thermal treatment conditions (solvothermal versus microwave) and solvent polarity on the morphology and emission of phloroglucinol-based nitrogen-doped carbon dots. Nanoscale 2021, 13, $3070-3078$. [CrossRef]

120. Crista, D.; Esteves da Silva, J.C.G.; Pinto da Silva, L. Evaluation of different bottom-up routes for the fabrication of carbon dots. Nanomaterials 2020, 10, 1316. [CrossRef]

121. Rigodanza, F.; Burian, M.; Arcudi, F.; Đorđević, L.; Amenitsch, H.; Prato, M. Snapshots into carbon dots formation through a combined spectroscopic approach. Nat. Commun. 2021, 12,1-9. [CrossRef]

122. Zhang, X.; Wang, S.; Liu, M.; Yang, B.; Feng, L.; Ji, Y.; Tao, L.; Wei, Y. Size tunable fluorescent nano-graphite oxides: Preparation and cell imaging applications. Phys. Chem. Chem. Phys. 2013, 15, 19013-19018. [CrossRef]

123. Mohammed, L.J.; Omer, K.M. Dual functional highly luminescence B, N Co-doped carbon nanodots as nanothermometer and $\mathrm{Fe} 3+/ \mathrm{Fe} 2+$ sensor. Sci. Rep. 2020, 10, 1-12. [CrossRef] [PubMed]

124. Gomez, I.J.; Arnaiz, B.; Cacioppo, M.; Arcudi, F.; Prato, M. Nitrogen-doped carbon nanodots for bioimaging and delivery of paclitaxel. J. Mater. Chem. B 2018, 6, 5540-5548. [CrossRef] [PubMed]

125. Ren, X.; Liu, J.; Ren, J.; Tang, F.; Meng, X. One-pot synthesis of active copper-containing carbon dots with laccase-like activities Nanoscale 2015, 7, 19641-19646. [CrossRef] [PubMed] 
126. Wang, Y.; Godin, R.; Durrant, J.R.; Tang, J. Efficient Hole Trapping in Carbon Dot/Oxygen-Modified Carbon Nitride Heterojunction Photocatalysts for Enhanced Methanol Production from $\mathrm{CO}_{2}$ under Neutral Conditions. Angew. Chemie Int. Ed. 2021, 60, 20811-20816. [CrossRef] [PubMed]

127. Dong, Y.; Zhou, N.; Lin, X.; Lin, J.; Chi, Y.; Chen, G. Extraction of electrochemiluminescent oxidized carbon quantum dots from activated carbon. Chem. Mater. 2010, 22, 5895-5899. [CrossRef]

128. Zhao, Q.L.; Zhang, Z.L.; Huang, B.H.; Peng, J.; Zhang, M.; Pang, D.W. Facile preparation of low cytotoxicity fluorescent carbon nanocrystals by electrooxidation of graphite. Chem. Commun. 2008, 5116-5118. [CrossRef]

129. Liu, H.; Ye, T.; Mao, C. Fluorescent carbon nanoparticles derived from candle soot. Angew. chemie 2007, 119, 6593-6595. [CrossRef]

130. Liu, H.; Li, Z.; Sun, Y.; Geng, X.; Hu, Y.; Meng, H.; Ge, J.; Qu, L. Synthesis of Luminescent Carbon Dots with Ultrahigh Quantum Yield and Inherent Folate Receptor-Positive Cancer Cell Targetability. Sci. Rep. 2018, 8, 1-8. [CrossRef]

131. Michaud, V.; Pracht, J.; Schilfarth, F.; Damm, C.; Platzer, B.; Haines, P.; Harreiß, C.; Guldi, D.M.; Spiecker, E.; Peukert, W. Well-separated water-soluble carbon dots via gradient chromatography. Nanoscale 2021, 13, 13116-13128. [CrossRef]

132. Zhu, C.; Yang, S.; Sun, J.; He, P.; Yuan, N.; Ding, J.; Mo, R.; Wang, G.; Ding, G.; Xie, X. Deep ultraviolet emission photoluminescence and high luminescece efficiency of ferric passivated graphene quantum dots: Strong negative inductive effect of Fe. Synth. Met. 2015, 209, 468-472. [CrossRef]

133. Bourlinos, A.B.; Rathi, A.K.; Gawande, M.B.; Hola, K.; Goswami, A.; Kalytchuk, S.; Karakassides, M.A.; Kouloumpis, A.; Gournis, D.; Deligiannakis, Y.; et al. Fe(III)-functionalized carbon dots-Highly efficient photoluminescence redox catalyst for hydrogenations of olefins and decomposition of hydrogen peroxide. Appl. Mater. Today 2017, 7, 179-184. [CrossRef]

134. Yang, W.; Huang, T.T.; Zhao, M.; Luo, F.; Weng, W.; Wei, Q.; Lin, Z.; Chen, G. High peroxidase-like activity of iron and nitrogen co-doped carbon dots and its application in immunosorbent assay. Talanta 2017, 164, 1-6. [CrossRef] [PubMed]

135. Ni, T.; Li, Q.; Yan, Y.; Wang, F.; Cui, X.; Yang, Z.; Wang, Y.; Yang, Z.; Chang, K.; Liu, G. N,fe-doped carbon dot decorated gear-shaped wo3 for highly efficient UV-VIS-NIR-driven photocatalytic performance. Catalysts 2020, 10, 1-14. [CrossRef]

136. Yang, M.; Feng, T.; Chen, Y.; Zhao, X.; Yang, B. Ionic-State Cobalt and Iron Co-doped Carbon Dots with Superior Electrocatalytic Activity for the Oxygen Evolution Reaction. ChemElectroChem 2019, 6, 2088-2094. [CrossRef]

137. Liu, H.; Sun, Y.; Yang, J.; Hu, Y.; Yang, R.; Li, Z.; Qu, L.; Lin, Y. High performance fluorescence biosensing of cysteine in human serum with superior specificity based on carbon dots and cobalt-derived recognition. Sensors Actuators, B Chem. 2019, 280, 62-68. [CrossRef]

138. Guo, X.L.; Ding, Z.Y.; Deng, S.M.; Wen, C.C.; Shen, X.C.; Jiang, B.P.; Liang, H. A novel strategy of transition-metal doping to engineer absorption of carbon dots for near-infrared photothermal/photodynamic therapies. Carbon N. Y. 2018, 134, 519-530. [CrossRef]

139. Liu, Y.; Wu, P.; Wu, X.; Ma, C.; Luo, S.; Xu, M.; Li, W.; Liu, S. Nitrogen and copper (II) co-doped carbon dots for applications in ascorbic acid determination by non-oxidation reduction strategy and cellular imaging. Talanta 2020, 210, 120649. [CrossRef]

140. Wu, W.; Zhan, L.; Fan, W.; Song, J.; Li, X.; Li, Z.; Wang, R.; Zhang, J.; Zheng, J.; Wu, M.; et al. Cu-N Dopants Boost Electron Transfer and Photooxidation Reactions of Carbon Dots. Angew. Chemie 2015, 127, 6640-6644. [CrossRef]

141. Wang, X.; Cheng, Z.; Zhou, Y.; Tammina, S.K.; Yang, Y. A double carbon dot system composed of N, Cl-doped carbon dots and N, $\mathrm{Cu}$-doped carbon dots as peroxidase mimics and as fluorescent probes for the determination of hydroquinone by fluorescence. Microchim. Acta 2020, 187, 1-8. [CrossRef]

142. Yang, M.; Tang, Q.; Meng, Y.; Liu, J.; Feng, T.; Zhao, X.; Zhu, S.; Yu, W.; Yang, B. Reversible “off-On” Fluorescence of Zn2+Passivated Carbon Dots: Mechanism and Potential for the Detection of EDTA and Zn2+. Langmuir 2018, 34, 7767-7775. [CrossRef]

143. Wang, Y.; Zhang, Y.; Jia, M.; Meng, H.; Li, H.; Guan, Y.; Feng, L. Functionalization of Carbonaceous Nanodots from MnIICoordinating Functional Knots. Chem. - A Eur. J. 2015, 21, 14843-14850. [CrossRef] [PubMed]

144. Cai, Y.; Fu, J.; Zhou, Y.; Chang, Y.-C.; Min, Q.; Zhu, J.-J.; Lin, Y.; Zhu, W. Insights on forming N, O-coordinated Cu single-atom catalysts for electrochemical reduction $\mathrm{CO}_{2}$ to methane. Nat. Commun. 2021, 12,1-9.

145. Qu, J.; Zhang, X.; Zhang, S.; Wang, Z.; Yu, Y.; Ding, H.; Tang, Z.; Heng, X.; Wang, R.; Jing, S. A facile co-crystallization approach to fabricate two-component carbon dot composites showing time-dependent evolutive room temperature phosphorescence colors. Nanoscale Adv. 2021, 3, 5053-5061. [CrossRef]

146. Sun, Y.; Liu, S.; Sun, L.; Wu, S.; Hu, G.; Pang, X.; Smith, A.T.; Hu, C.; Zeng, S.; Wang, W. Ultralong lifetime and efficient room temperature phosphorescent carbon dots through multi-confinement structure design. Nat. Commun. 2020, 11, 1-11. [CrossRef]

147. Guo, X.; Pan, Q.; Song, X.; Guo, Q.; Zhou, S.; Qiu, J.; Dong, G. Embedding carbon dots in Eu3+-doped metal-organic framework for label-free ratiometric fluorescence detection of Fe3+ ions. J. Am. Ceram. Soc. 2021, 104, 886-895. [CrossRef]

148. Sun, M.; Han, Y.; Yuan, X.; Jing, P.; Zhang, L.; Zhao, J.; Zheng, Y. Efficient full-color emitting carbon-dot-based composite phosphors by chemical dispersion. Nanoscale 2020, 12, 15823-15831. [CrossRef]

149. Zhou, Z.; Ushakova, E.V.; Liu, E.; Bao, X.; Li, D.; Zhou, D.; Tan, Z.; Qu, S.; Rogach, A.L. A co-crystallization induced surface modification strategy with cyanuric acid modulates the bandgap emission of carbon dots. Nanoscale 2020, 12, 10987-10993. [CrossRef]

150. Li, S.; Ji, K.; Zhang, M.; He, C.; Wang, J.; Li, Z. Boosting the photocatalytic $\mathrm{CO}_{2}$ reduction of metal-organic frameworks by encapsulating carbon dots. Nanoscale 2020, 12, 9533-9540. [CrossRef] 
151. Cheng, S.; Ye, T.; Mao, H.; Wu, Y.; Jiang, W.; Ban, C.; Yin, Y.; Liu, J.; Xiu, F.; Huang, W. Electrostatically assembled carbon dots/boron nitride nanosheet hybrid nanostructures for thermal quenching-resistant white phosphors. Nanoscale 2020, 12, 524-529. [CrossRef]

152. Liu, L.; Wu, Y.; Zhang, P.; Li, F.; Liu, J.; Zhao, J.-F.; Huo, F.; Zhao, Q.; Huang, W. Green-Synthesized Phosphorescent Carbon Dot Composite for Multilevel Anti-Counterfeiting. Nanoscale Adv. 2021, 3, 4536-4540.

153. Li, Q.; Wang, S.; Sun, Z.; Tang, Q.; Liu, Y.; Wang, L.; Wang, H.; Wu, Z. Enhanced CH4 selectivity in $\mathrm{CO}_{2}$ photocatalytic reduction over carbon quantum dots decorated and oxygen doping g-C3N4. Nano Res. 2019, 12, 2749-2759. [CrossRef]

154. Lv, K.; Suo, W.; Shao, M.; Zhu, Y.; Wang, X.; Feng, J.; Fang, M. Nitrogen doped MoS2 and nitrogen doped carbon dots composite catalyst for electroreduction $\mathrm{CO}_{2}$ to $\mathrm{CO}$ with high Faradaic efficiency. Nano Energy 2019, 63, 103834. [CrossRef]

155. Shen, H.; Peppel, T.; Strunk, J.; Sun, Z. Photocatalytic Reduction of $\mathrm{CO}_{2}$ by Metal-Free-Based Materials: Recent Advances and Future Perspective. Sol. RRL 2020, 4, 1900546. [CrossRef]

156. Liang, J.; Jiang, Z.; Wong, P.K.; Lee, C. Recent Progress on Carbon Nitride and Its Hybrid Photocatalysts for $\mathrm{CO}_{2}$ Reduction. Sol. RRL 2021, 2000478, 1-25. [CrossRef]

157. Li, X.; Yu, J.; Wageh, S.; Al-ghamdi, A.A.; Xie, J. Graphene in Photocatalysis: A Review. Small 2016, 12, 6640-6696. [CrossRef]

158. Wang, Y.; Xia, Q.; Bai, X.; Ge, Z.; Yang, Q.; Yin, C. Carbothermal activation synthesis of 3D porous g- $\mathrm{C}_{3} \mathrm{~N}_{4} / \mathrm{carbon}$ nanosheets composite with superior performance for $\mathrm{CO}_{2}$ photoreduction. Appl. Catal. B Environ. 2018, 239, 196-203. [CrossRef]

159. Hsu, H.; Shown, I.; Wei, H.; Chang, Y.; Du, H.; Lin, Y.; Tseng, C.; Wang, C.; Chen, L.; Lin, Y.; et al. Graphene oxide as a promising photocatalyst for $\mathrm{CO}_{2}$ to methanol conversion. Nanoscale 2013, 5, 262-268. [CrossRef]

160. Yadav, D.; Yadav, R.K.; Kumar, A.; Park, N.J.; Baeg, J.O. Functionalized Graphene Quantum Dots as Efficient Visible-Light Photocatalysts for Selective Solar Fuel Production from $\mathrm{CO}_{2}$. ChemCatChem 2016, 8, 3389-3393. [CrossRef]

161. Sahu, S.; Liu, Y.; Wang, P.; Bunker, C.E.; Fernando, K.A.S.; Lewis, W.K.; Guliants, E.A.; Yang, F.; Wang, J.; Sun, Y.P. Visible-light photoconversion of carbon dioxide into organic acids in an aqueous solution of carbon dots. Langmuir 2014, 30, 8631-8636. [CrossRef]

162. Duan, X.; Xu, J.; Wei, Z.; Ma, J.; Guo, S.; Wang, S.; Liu, H.; Dou, S. Metal-free carbon materials for $\mathrm{CO}_{2}$ electrochemical reduction Adv. Mater. 2017, 29, 1701784. [CrossRef]

163. Varela, A.S.; Ju, W.; Bagger, A.; Franco, P.; Rossmeisl, J.; Strasser, P. Electrochemical reduction of $\mathrm{CO}_{2}$ on metal-nitrogen-doped carbon catalysts. ACS Catal. 2019, 9, 7270-7284. [CrossRef]

164. Kumar, B.; Asadi, M.; Pisasale, D.; Sinha-Ray, S.; Rosen, B.A.; Haasch, R.; Abiade, J.; Yarin, A.L.; Salehi-Khojin, A. Renewable and metal-free carbon nanofibre catalysts for carbon dioxide reduction. Nat. Commun. 2013, 4, 1-8. [CrossRef]

165. Wu, J.; Yadav, R.M.; Liu, M.; Sharma, P.P.; Tiwary, C.S.; Ma, L.; Zou, X.; Zhou, X.-D.; Yakobson, B.I.; Lou, J. Achieving highly efficient, selective, and stable $\mathrm{CO}_{2}$ reduction on nitrogen-doped carbon nanotubes. ACS Nano 2015, 9, 5364-5371. [CrossRef] [PubMed]

166. Sharma, P.P.; Wu, J.; Yadav, R.M.; Liu, M.; Wright, C.J.; Tiwary, C.S.; Yakobson, B.I.; Lou, J.; Ajayan, P.M.; Zhou, X. Nitrogen-doped carbon nanotube arrays for high-efficiency electrochemical reduction of $\mathrm{CO}_{2}$ : On the understanding of defects, defect density, and selectivity. Angew. Chemie 2015, 127, 13905-13909. [CrossRef]

167. Zhang, S.; Kang, P.; Ubnoske, S.; Brennaman, M.K.; Song, N.; House, R.L.; Glass, J.T.; Meyer, T.J. Polyethylenimine-enhanced electrocatalytic reduction of $\mathrm{CO}_{2}$ to formate at nitrogen-doped carbon nanomaterials. J. Am. Chem. Soc. 2014, 136, 7845-7848. [CrossRef]

168. Li, J.; Zan, W.-Y.; Kang, H.; Dong, Z.; Zhang, X.; Lin, Y.; Mu, Y.-W.; Zhang, F.; Zhang, X.-M.; Gu, J. Graphitic-N highly doped graphene-like carbon: A superior metal-free catalyst for efficient reduction of $\mathrm{CO}_{2}$. Appl. Catal. B Environ. 2021, $298,120510$. [CrossRef]

169. Wu, J.; Liu, M.; Sharma, P.P.; Yadav, R.M.; Ma, L.; Yang, Y.; Zou, X.; Zhou, X.-D.; Vajtai, R.; Yakobson, B.I. Incorporation of nitrogen defects for efficient reduction of $\mathrm{CO}_{2}$ via two-electron pathway on three-dimensional graphene foam. Nano Lett. 2016, 16, 466-470. [CrossRef]

170. Wang, H.; Chen, Y.; Hou, X.; Ma, C.; Tan, T. Nitrogen-doped graphenes as efficient electrocatalysts for the selective reduction of carbon dioxide to formate in aqueous solution. Green Chem. 2016, 18, 3250-3256. [CrossRef]

171. Sreekanth, N.; Nazrulla, M.A.; Vineesh, T.V.; Sailaja, K.; Phani, K.L. Metal-free boron-doped graphene for selective electroreduction of carbon dioxide to formic acid/formate. Chem. Commun. 2015, 51, 16061-16064. [CrossRef]

172. Liu, Y.; Chen, S.; Quan, X.; Yu, H. Efficient electrochemical reduction of carbon dioxide to acetate on nitrogen-doped nanodiamond J. Am. Chem. Soc. 2015, 137, 11631-11636. [CrossRef]

173. Song, Y.; Chen, W.; Zhao, C.; Li, S.; Wei, W.; Sun, Y. Metal-free nitrogen-doped mesoporous carbon for electroreduction of $\mathrm{CO}_{2}$ to ethanol. Angew. Chemie 2017, 129, 10980-10984. [CrossRef]

174. Liu, Y.; Zhang, Y.; Cheng, K.; Quan, X.; Fan, X.; Su, Y.; Chen, S.; Zhao, H.; Zhang, Y.; Yu, H. Selective electrochemical reduction of carbon dioxide to ethanol on a boron-and nitrogen-Co-doped nanodiamond. Angew. Chemie 2017, 129, 15813-15817. [CrossRef]

175. Wang, Y.; Chen, J.; Wang, G.; Li, Y.; Wen, Z. Perfluorinated covalent triazine framework derived hybrids for the highly selective electroconversion of carbon dioxide into methane. Angew. Chemie Int. Ed. 2018, 57, 13120-13124. [CrossRef] [PubMed]

176. Ma, S.; Sadakiyo, M.; Luo, R.; Heima, M.; Yamauchi, M.; Kenis, P.J.A. One-step electrosynthesis of ethylene and ethanol from $\mathrm{CO}_{2}$ in an alkaline electrolyzer. J. Power Sources 2016, 301, 219-228. [CrossRef] 
177. Zou, X.; Liu, M.; Wu, J.; Ajayan, P.M.; Li, J.; Liu, B.; Yakobson, B.I. How nitrogen-doped graphene quantum dots catalyze electroreduction of $\mathrm{CO}_{2}$ to hydrocarbons and oxygenates. ACS Catal. 2017, 7, 6245-6250. [CrossRef]

178. Montoya, J.H.; Shi, C.; Chan, K.; Nørskov, J.K. Theoretical insights into a CO dimerization mechanism in $\mathrm{CO}_{2}$ electroreduction. J. Phys. Chem. Lett. 2015, 6, 2032-2037. [CrossRef]

179. Ji, S.; Chen, Y.; Wang, X.; Zhang, Z.; Wang, D.; Li, Y. Chemical synthesis of single atomic site catalysts. Chem. Rev. 2020, 120, 11900-11955. [CrossRef] [PubMed]

180. Zhao, L.; Zhang, Y.; Huang, L.-B.; Liu, X.-Z.; Zhang, Q.-H.; He, C.; Wu, Z.-Y.; Zhang, L.-J.; Wu, J.; Yang, W. Cascade anchoring strategy for general mass production of high-loading single-atomic metal-nitrogen catalysts. Nat. Commun. 2019, 10, 1-11. [CrossRef]

181. Yang, H.B.; Hung, S.-F.; Liu, S.; Yuan, K.; Miao, S.; Zhang, L.; Huang, X.; Wang, H.-Y.; Cai, W.; Chen, R. Atomically dispersed Ni (I) as the active site for electrochemical $\mathrm{CO}_{2}$ reduction. Nat. Energy 2018, 3, 140-147. [CrossRef]

182. Liu, S.; Tao, H.; Zeng, L.; Liu, Q.; Xu, Z.; Liu, Q.; Luo, J.-L. Shape-dependent electrocatalytic reduction of $\mathrm{CO}_{2}$ to $\mathrm{CO}_{\text {on }}$ triangular silver nanoplates. J. Am. Chem. Soc. 2017, 139, 2160-2163. [CrossRef]

183. Hsieh, Y.-C.; Senanayake, S.D.; Zhang, Y.; Xu, W.; Polyansky, D.E. Effect of chloride anions on the synthesis and enhanced catalytic activity of silver nanocoral electrodes for $\mathrm{CO}_{2}$ electroreduction. Acs Catal. 2015, 5, 5349-5356. [CrossRef]

184. Lu, Q.; Rosen, J.; Zhou, Y.; Hutchings, G.S.; Kimmel, Y.C.; Chen, J.G.; Jiao, F. A selective and efficient electrocatalyst for carbon dioxide reduction. Nat. Commun. 2014, 5, 1-6. [CrossRef] [PubMed]

185. Hori, Y.I. Electrochemical $\mathrm{CO}_{2}$ reduction on metal electrodes. In Modern Aspects of Electrochemistry; Springer: New York, NY, USA, 2008; pp. 89-189.

186. Zhu, W.; Zhang, Y.-J.; Zhang, H.; Lv, H.; Li, Q.; Michalsky, R.; Peterson, A.A.; Sun, S. Active and selective conversion of $\mathrm{CO}_{2}$ to CO on ultrathin Au nanowires. J. Am. Chem. Soc. 2014, 136, 16132-16135. [CrossRef] [PubMed]

187. Mistry, H.; Reske, R.; Zeng, Z.; Zhao, Z.-J.; Greeley, J.; Strasser, P.; Cuenya, B.R. Exceptional size-dependent activity enhancement in the electroreduction of $\mathrm{CO}_{2}$ over Au nanoparticles. J. Am. Chem. Soc. 2014, 136, 16473-16476. [CrossRef]

188. Seh, Z.W.; Kibsgaard, J.; Dickens, C.F.; Chorkendorff, I.B.; Nørskov, J.K.; Jaramillo, T.F. Combining theory and experiment in electrocatalysis: Insights into materials design. Science 2017, 355, eaad4998. [CrossRef]

189. Hansen, H.A.; Varley, J.B.; Peterson, A.A.; Nørskov, J.K. Understanding trends in the electrocatalytic activity of metals and enzymes for $\mathrm{CO}_{2}$ reduction to CO. J. Phys. Chem. Lett. 2013, 4, 388-392. [CrossRef]

190. Innocent, B.; Liaigre, D.; Pasquier, D.; Ropital, F.; Léger, J.-M.; Kokoh, K.B. Electro-reduction of carbon dioxide to formate on lead electrode in aqueous medium. J. Appl. Electrochem. 2009, 39, 227. [CrossRef]

191. Zhang, S.; Kang, P.; Meyer, T.J. Nanostructured tin catalysts for selective electrochemical reduction of carbon dioxide to formate. J. Am. Chem. Soc. 2014, 136, 1734-1737. [CrossRef]

192. Koh, J.H.; Won, D.H.; Eom, T.; Kim, N.-K.; Jung, K.D.; Kim, H.; Hwang, Y.J.; Min, B.K. Facile $\mathrm{CO}_{2}$ electro-reduction to formate via oxygen bidentate intermediate stabilized by high-index planes of Bi dendrite catalyst. ACS Catal. 2017, 7, 5071-5077. [CrossRef]

193. Li, F.; Zhao, S.-F.; Chen, L.; Khan, A.; MacFarlane, D.R.; Zhang, J. Polyethylenimine promoted electrocatalytic reduction of $\mathrm{CO}_{2}$ to $\mathrm{CO}$ in aqueous medium by graphene-supported amorphous molybdenum sulphide. Energy Environ. Sci. 2016, 9, $216-223$. [CrossRef]

194. Gao, D.; Sinev, I.; Scholten, F.; Arán-Ais, R.M.; Divins, N.J.; Kvashnina, K.; Timoshenko, J.; Roldan Cuenya, B. Selective CO 2 Electroreduction to Ethylene and Multicarbon Alcohols via Electrolyte-Driven Nanostructuring. Angew. Chemie 2019, 131, 17203-17209. [CrossRef]

195. Choi, C.; Cheng, T.; Flores Espinosa, M.; Fei, H.; Duan, X.; Goddard III, W.A.; Huang, Y. A highly active star decahedron Cu nanocatalyst for hydrocarbon production at low overpotentials. Adv. Mater. 2019, 31, 1805405. [CrossRef] [PubMed]

196. Grosse, P.; Gao, D.; Scholten, F.; Sinev, I.; Mistry, H.; Roldan Cuenya, B. Dynamic changes in the structure, chemical state and catalytic selectivity of $\mathrm{Cu}$ nanocubes during $\mathrm{CO}_{2}$ electroreduction: Size and support effects. Angew. Chemie Int. Ed. 2018, 57, 6192-6197. [CrossRef]

197. Yan, Y.; Ke, L.; Ding, Y.; Zhang, Y.; Rui, K.; Lin, H.; Zhu, J. Recent advances in Cu-based catalysts for electroreduction of carbon dioxide. Mater. Chem. Front. 2021, 5, 2668-2683. [CrossRef]

198. Li, Y.; Kim, D.; Louisia, S.; Xie, C.; Kong, Q.; Yu, S.; Lin, T.; Aloni, S.; Fakra, S.C.; Yang, P. Electrochemically scrambled nanocrystals are catalytically active for $\mathrm{CO}_{2}$-to-multicarbons. Proc. Natl. Acad. Sci. USA 2020, 117, 9194-9201. [CrossRef]

199. Wang, S.; Kou, T.; Baker, S.E.; Duoss, E.B.; Li, Y. Recent progress in electrochemical reduction of $\mathrm{CO}_{2}$ by oxide-derived copper catalysts. Mater. Today Nano 2020, 100096. [CrossRef]

200. Lv, J.; Jouny, M.; Luc, W.; Zhu, W.; Zhu, J.; Jiao, F. A highly porous copper electrocatalyst for carbon dioxide reduction. Adv. Mater. 2018, 30, 1803111. [CrossRef]

201. Kim, J.; Choi, W.; Park, J.W.; Kim, C.; Kim, M.; Song, H. Branched copper oxide nanoparticles induce highly selective ethylene production by electrochemical carbon dioxide reduction. J. Am. Chem. Soc. 2019, 141, 6986-6994. [CrossRef] 